Rakenteiden Mekaniikka (Journal of Structural Mechanics)

vol. 54, nro. 1, 2021, s. 30-68

http://rakenteidenmekaniikka.journal.fi/index

https://doi.org/10.23998/rm.95447

(C) 2021 kirjoittaja

Vapaasti saatavilla CC BY 4.0 -lisenssin mukaisesti

\title{
Taivutuksesta ja väännöstä, osa II: Elementtimenetelmä
}

\author{
Jukka Aalto
}

Tiivistelmä Artikkelin ensimmäisessä osassa [1] johdettiin kuormituksen alaiselle suoralle palkille yhdistetty taivutus- ja vääntöteoria. Se perustui neljää käyristymisfunktiota käyttäen muodostettuun yksinkertaiseen siirtymäotaksumaan. Tässä artikkelin toisessa osassa esitellään, kuinka tätä teoriaa voidaan soveltaa käytännön tehtäviin elementtimenetelmän tekniikoita hyväksi käyttäen. Tehtävä voidaan jakaa seuraaviin osiin: 1) käyristymisfunktioiden määrittäminen, 2) poikkileikkaussuureiden määrittäminen, 3) palkkitehtävän ratkaiseminen ja 4) poikki-leikkauksen jännitysjakauman määrittäminen. Lopuksi esitetään laskentaesimerkki.

Avainsanat: palkkiteoria, taivutus, vääntö, leikkausmuodonmuutos, käyristymisfunktio, reunaarvotehtävä, heikko muoto, elementtimenetelmä

Vastaanotettu: 4.6.2020. Hyväksytty: 21.10.2020. Julkaistu verkossa: 13.4.2021.

\section{Johdanto}

Samoin kuin artikkelin ensimmäisessä osassa, palkin jäykkyyttä kuvaaville suureille, kuten taivutusjäykkyydelle $E I_{z}$, käytetään tässä kaksikirjaimisia symboleja. Jos poikkileikkaus on homogeeninen ja kimmomoduuli $E$ vakio, taivutusjäykkyys $E I_{z}$ on kimmomoduulin $E$ ja jäyhyysmomentin $I_{z}$ tulo.

Viitattaessa artikkelin ensimmäisen osan kaavoihin, kaavanumeron eteen lisätään I-. Esimerkiksi kaavanumero (I-21) alla viittaa artikkelin ensimmäisen osan [1] kaavaan (21). 


\section{Käyristymisfunktioiden määrittäminen}

\section{Heikot muodot}

Käyristymisfunktioille $\Phi(y, z), \Psi_{x}(y, z), \Psi_{y}(y, z)$ ja $\Psi_{z}(y, z)$ esitettyjen reuna-arvotehtävien (I-21) numeerista ratkaisemista varten johdettiin niiden heikot muodot (I-22), jotka ovat

$$
\begin{gathered}
\int_{A} G\left(\frac{\partial \hat{\Phi}}{\partial y} \frac{\partial \Phi}{\partial y}+\frac{\partial \hat{\Phi}}{\partial z} \frac{\partial \Phi}{\partial z}\right) \mathrm{d} A=\int_{A} G\left(\frac{\partial \hat{\Phi}}{\partial y} z-\frac{\partial \hat{\Phi}}{\partial z} y\right) \mathrm{d} A, \\
\int_{A} G\left(\frac{\partial \hat{\Psi}_{x}}{\partial y} \frac{\partial \Psi_{x}}{\partial y}+\frac{\partial \hat{\Psi}_{x}}{\partial z} \frac{\partial \Psi_{x}}{\partial z}\right) \mathrm{d} A=\int_{A} E \hat{\Psi}_{x} \phi \mathrm{d} A, \\
\int_{A} G\left(\frac{\partial \hat{\Psi}_{y}}{\partial y} \frac{\partial \Psi_{y}}{\partial y}+\frac{\partial \hat{\Psi}_{y}}{\partial z} \frac{\partial \Psi_{y}}{\partial z}\right) \mathrm{d} A=\int_{A} E \hat{\Psi}_{y} y \mathrm{~d} A, \\
\int_{A} G\left(\frac{\partial \hat{\Psi}_{z}}{\partial y} \frac{\partial \Psi_{z}}{\partial y}+\frac{\partial \hat{\Psi}_{z}}{\partial z} \frac{\partial \Psi_{z}}{\partial z}\right) \mathrm{d} A=\int_{A} E \hat{\Psi}_{z} z \mathrm{~d} A,
\end{gathered}
$$

missä $A$ on poikkipinnan alue ja sen reuna sekä $\hat{\Phi}(y, z), \hat{\Psi}_{x}(y, z), \hat{\Psi}_{y}(y, z)$ ja $\hat{\Psi}_{z}(y, z)$ ovat mielivaltaisia testifunktioita. Yhtälössä (1b) oleva käyristymisfunktio $\phi(y, z)$ ajatellaan tunnetuksi. Se voidaan määrittää, kun käyristymisfunktio $\Phi(y, z)$ on ensin ratkaistu reuna-arvoprobleeman (1a) ratkaisuna, kaavalla

$$
\phi(y, z)=\Phi(y, z)+\Delta_{\Phi}-z_{\mathrm{T}} y+y_{\mathrm{T}} z
$$

missä $\Delta_{\Phi}$ on vakio sekä $y_{\mathrm{T}}$ ja $z_{\mathrm{T}}$ vääntökeskiön koordinaatit. Reuna-arvotehtävien (1) ratkaisuna saatavat käyristymisfunktiot ovat vakiota vailla yksikäsitteisiä. Sellaisiksi ne saadaan vaatimalla, että ne häviävät valitussa nollapisteessä $\mathrm{P}_{0}$.

\section{Elementtiyhtälöt}

Muodostettaessa heikkoja muotoja (1) vastaavat elementtiyhtälöt, otetaan käyristymisfunktioille $\Phi(y, z), \Psi_{x}(y, z), \Psi_{y}(y, z)$ ja $\Psi_{z}(y, z)$ elementtiapproksimaatiot

$$
\begin{aligned}
& \Phi(y, z)=\sum_{i=1}^{M} N_{i}(y, z) \Phi_{i}, \Psi_{x}(y, z)=\sum_{i=1}^{M} N_{i}(y, z) \Psi_{x i}, \\
& \Psi_{y}(y, z)=\sum_{i=1}^{M} N_{i}(y, z) \Psi_{y i}, \quad \Psi_{z}(y, z)=\sum_{i=1}^{M} N_{i}(y, z) \Psi_{z i},
\end{aligned}
$$

missä $\Phi_{i}, \Psi_{x i}, \Psi_{y i}$ ja $\Psi_{z i}$ ovat käyristymisfunktioiden solmuarvot, $N_{i}$ ovat muotofunktiot sekä $M$ on solmujen lukumäärä. Testifunktioille $\hat{\Phi}(y, z), \hat{\Psi}_{x}(y, z), \hat{\Psi}_{y}(y, z)$ ja $\hat{\Psi}_{z}(y, z)$ otetaan vastaavat esitykset. Heikkojen muotojen (1) diskretointi tavanomaiseen tapaan johtaa seuraaviin yhtälöihin

$$
\mathbf{K \mathbf { a } _ { \Phi }}=\mathbf{R}_{\Phi}, \quad \mathbf{K \mathbf { a } _ { x }}=\mathbf{R}_{x}, \quad \mathbf{K \mathbf { a } _ { y }}=\mathbf{R}_{y}, \quad \mathbf{K} \mathbf{a}_{z}=\mathbf{R}_{z},
$$

missä 


$$
\mathbf{a}_{\Phi}=\left\{\begin{array}{c}
\Phi_{1} \\
\vdots \\
\Phi_{M}
\end{array}\right\}, \quad \mathbf{a}_{x}=\left\{\begin{array}{c}
\Psi_{x 1} \\
\vdots \\
\Psi_{x M}
\end{array}\right\}, \quad \mathbf{a}_{y}=\left\{\begin{array}{c}
\Psi_{y 1} \\
\vdots \\
\Psi_{y M}
\end{array}\right\}, \quad \mathbf{a}_{z}=\left\{\begin{array}{c}
\Psi_{z 1} \\
\vdots \\
\Psi_{z M}
\end{array}\right\}
$$

ovat käyristymisfunktion systeemisolmuarvojen muodostamat pystyvektorit. Systeemimatriisin $\mathbf{K}$ ja systeemivektoreiden $\mathbf{R}_{\Phi}, \mathbf{R}_{x}, \mathbf{R}_{y}$ ja $\mathbf{R}_{z}$ alkiot ovat

$$
K_{i j}=\int_{A} G\left(\frac{\partial N_{i}}{\partial y} \frac{\partial N_{j}}{\partial y}+\frac{\partial N_{i}}{\partial z} \frac{\partial N_{j}}{\partial z}\right) \mathrm{d} A
$$

ja

$$
R_{\Phi i}=\int_{A} G\left(\frac{\partial N_{i}}{\partial y} z-\frac{\partial N_{i}}{\partial z} y\right) \mathrm{d} A, \quad R_{x i}=\int_{A} E N_{i} \phi \mathrm{d} A, \quad R_{y i}=\int_{A} E N_{i} y \mathrm{~d} A, \quad R_{z i}=\int_{A} E N_{i} z \mathrm{~d} A .
$$

On huomattavaa, että kaikilla neljällä yhtälöryhmällä (4) on sama kerroinmatriisi. Jotta niille saadaan yksikäsitteiset ratkaisut, valitaan elementtiverkon tietty solmu $r$ nollapisteeksi $P_{0}$ ja vaaditaan, että sen solmuarvot $\Phi_{r}, \Psi_{x r}, \Psi_{y r}$ ja $\Psi_{z r}$ häviävät. Tämä tapahtuu helpoimmin korvaamalla systeemimatriisin $\mathbf{K} r$ :s vaaka- ja pystyrivi nollarivillä ja panemalla vastaavaksi diagonaalitermiksi ykkönen sekä korvaamalla systeemivektorien $\mathbf{R}_{\Phi} \mathbf{R}_{x} \mathbf{R}_{y}$ ja $\mathbf{R}_{z} r$ :s alkio nollalla.

\section{Lineaarinen kolmioelementti}

Liitteessä A on johdettu lauseke systeemimatriisia $\mathbf{K}$ vastaavalle elementtimatriisille $\mathbf{K}^{e}$ lineaarisen kolmioelementin tapauksessa, jossa kimmomoduuli $E^{e}$ ja liukumoduuli $G^{e}$ ja ovat vakioita elementin alueella. Sille saatiin kaava

$$
\mathbf{K}^{e}=\frac{G^{e}}{4 A^{e}}\left[\begin{array}{lll}
b_{1} b_{1}+c_{1} c_{1} & b_{1} b_{2}+c_{1} c_{2} & b_{1} b_{3}+c_{1} c_{3} \\
b_{2} b_{1}+c_{2} c_{1} & b_{2} b_{2}+c_{2} c_{2} & b_{2} b_{3}+c_{2} c_{3} \\
b_{3} b_{1}+c_{3} c_{1} & b_{3} b_{2}+c_{3} c_{2} & b_{3} b_{3}+c_{3} c_{3}
\end{array}\right],
$$

missä $A^{e}$ on elementin pinta-ala ja

$$
\begin{aligned}
& b_{1}=z_{2}^{e}-z_{3}^{e}, \quad b_{2}=z_{3}^{e}-z_{1}^{e}, \quad b_{3}=z_{1}^{e}-z_{2}^{e}, \\
& c_{1}=y_{3}^{e}-y_{2}^{e}, \quad c_{2}=y_{1}^{e}-y_{3}^{e}, \quad c_{3}=y_{2}^{e}-y_{1}^{e} .
\end{aligned}
$$

Liitteessä A on myös johdettu lausekkeet systeemivektoreita $\mathbf{R}_{\Phi}, \mathbf{R}_{x}, \mathbf{R}_{y}$ ja $\mathbf{R}_{z}$ vastaaville elementtivektoreille $\mathbf{R}_{\Phi}^{e}, \mathbf{R}_{x}^{e}, \mathbf{R}_{y}^{e}$ ja $\mathbf{R}_{z}^{e}$. Niille saatiin kaavat

$$
\begin{gathered}
\mathbf{R}_{\Phi}^{e}=\frac{G^{e}}{2}\left\{\begin{array}{l}
b_{1} \bar{z}^{e}-c_{1} \bar{y}^{e} \\
b_{2} \bar{z}^{e}-c_{2} \bar{y}^{e} \\
b_{3} \bar{z}^{e}-c_{3} \bar{y}^{e}
\end{array}\right\}, \\
\mathbf{R}_{x}^{e}=\frac{E^{e} A^{e}}{12}\left\{\begin{array}{l}
2 \phi_{1}^{e}+\phi_{2}^{e}+\phi_{3}^{e} \\
\phi_{1}^{e}+2 \phi_{2}^{e}+\phi_{3}^{e} \\
\phi_{1}^{e}+\phi_{2}^{e}+2 \phi_{3}^{e}
\end{array}\right\},
\end{gathered}
$$




$$
\begin{aligned}
& \mathbf{R}_{y}^{e}=\frac{E^{e} A^{e}}{12}\left\{\begin{array}{l}
2 y_{1}^{e}+y_{2}^{e}+y_{3}^{e} \\
y_{1}^{e}+2 y_{2}^{e}+y_{3}^{e} \\
y_{1}^{e}+y_{2}^{e}+2 y_{3}^{e}
\end{array}\right\}, \\
& \mathbf{R}_{z}^{e}=\frac{E^{e} A^{e}}{12}\left\{\begin{array}{l}
2 z_{1}^{e}+z_{2}^{e}+z_{3}^{e} \\
z_{1}^{e}+2 z_{2}^{e}+z_{3}^{e} \\
z_{1}^{e}+z_{2}^{e}+2 z_{3}^{e}
\end{array}\right\} .
\end{aligned}
$$

Näissä kaavoissa $\phi_{i}^{e}$ ovat käyristymisfunktion $\phi$ elementtisolmuarvot sekä $y_{i}^{e}$ ja $z_{i}^{e}$ ovat elementtisolmujen koordinaatit sekä

$$
\bar{y}^{e}=\frac{y_{1}^{e}+y_{2}^{e}+y_{3}^{e}}{3}, \quad \bar{z}^{e}=\frac{z_{1}^{e}+z_{2}^{e}+z_{3}^{e}}{3}
$$

ovat elementin keskipisteen koordinaatit.

\section{Poikkileikkaukseen liittyvien suureiden määrittäminen}

\section{Poikkileikkaukseen liittyvät suureet}

Poikkileikkauksen $y, z$-koordinaatiston origo $\mathrm{O}$ asetetaan poikkileikkauksen vetojäykkyyskeskiöön. Käytännössä sen asema määritetään valitsemalla poikkileikkaukseen sopiva $y^{\prime}, z^{\prime}$-koordinaatisto. Tässä koordinaatistossa vetojäykkyyskeskiön koordinaatit saadaan kaavoilla

$$
y_{\mathrm{O}}^{\prime}=\frac{E S_{z}^{\prime}}{E A}, \quad z_{\mathrm{O}}^{\prime}=\frac{E S_{y}^{\prime}}{E A}
$$

missä

$$
E A=\int_{A} E \mathrm{~d} A, E S_{y}^{\prime}=\int_{A} E z^{\prime} \mathrm{d} A, E S_{z}^{\prime}=\int_{A} E y^{\prime} \mathrm{d} A .
$$

Taivutusjäykkyydet ja tulojäykkyys saadaan kaavoilla

$$
E I_{y}=\int_{A} E z^{2} \mathrm{~d} A, E I_{z}=\int_{A} E y^{2} \mathrm{~d} A, E I_{y z}=\int_{A} E y z \mathrm{~d} A .
$$

Vakio $\Delta_{\Phi}$ ja vääntökeskiön koordinaatit $y_{\mathrm{T}}$ ja $z_{\mathrm{T}}$ saadaan kaavoilla

missä

$$
\Delta_{\Phi}=-\frac{E S_{\Phi}}{E A}, \quad\left\{\begin{array}{l}
y_{\mathrm{T}} \\
z_{\mathrm{T}}
\end{array}\right\}=\frac{1}{E I_{y} E I_{z}-E I_{y z}^{2}}\left[\begin{array}{cc}
E I_{z} & E I_{y z} \\
E I_{y z} & E I_{y}
\end{array}\right]\left\{\begin{array}{c}
-E I_{y \Phi} \\
E I_{z \Phi}
\end{array}\right\},
$$

$$
E S_{\Phi}=\int_{A} E \Phi \mathrm{d} A, \quad E I_{y \Phi}=\int_{A} E z \Phi \mathrm{d} A, \quad E I_{z \Phi}=\int_{A} E y \Phi \mathrm{d} A .
$$

Leikkaus, vääntö- ja käyristymisjäykkyys saadaan kaavoilla

$$
G A=\int_{A} G \mathrm{~d} A, \quad G J=\int_{A} G\left[-\left(\frac{\partial \Phi}{\partial y}-z\right) z+\left(\frac{\partial \Phi}{\partial z}+y\right) y\right] \mathrm{d} A, \quad E I_{\phi}=\int_{A} E \phi^{2} \mathrm{~d} A .
$$

Leikkauskorjauskertoimet saadaan kaavalla 


$$
\left[\begin{array}{cc}
k_{y} & k_{y z} \\
k_{z y} & k_{z}
\end{array}\right]=\frac{1}{G A}\left[\begin{array}{cc}
E I_{z} & E I_{y z} \\
E I_{y z} & E I_{y}
\end{array}\right]\left[\begin{array}{cc}
E I_{y \Psi_{y}} & E I_{z \Psi_{y}} \\
E I_{y \Psi_{z}} & E I_{z \Psi_{z}}
\end{array}\right]^{-1}\left[\begin{array}{cc}
E I_{z} & E I_{y z} \\
E I_{y z} & E I_{y}
\end{array}\right],
$$

missä

$$
\begin{aligned}
& E I_{y \Psi_{y}}=\int_{A} E z \Psi_{y} \mathrm{~d} A, \quad E I_{z \Psi_{y}}=\int_{A} E y \Psi_{y} \mathrm{~d} A, \\
& E I_{y \Psi_{z}}=\int_{A} E z \Psi_{z} \mathrm{~d} A, \quad E I_{z \Psi_{z}}=\int_{A} E y \Psi_{z} \mathrm{~d} A .
\end{aligned}
$$

\section{Poikkileikkaussuureiden määrittäminen}

Elementtimenetelmää sovellettaessa on poikkileikkaussuureet käytännöllistä määrittää summana elementtiosuuksistaan. Esimerkiksi leikkausjäykkyydelle, vääntöjäykkyydelle ja käyristymisjäykkyydelle (20) saadaan

$$
G A=\sum_{e=1}^{N}(G A)^{e}, \quad G J=\sum_{e=1}^{N}(G J)^{e}, \quad E I_{\phi}=\sum_{e=1}^{N}\left(E I_{\phi}\right)^{e},
$$

missä niiden elementtiosuudet ovat $(G A)^{e}(G J)^{e}$ ja $\left(E I_{\phi}\right)^{e}$ sekä $N$ on elementtien lukumäärä. Liitteessä B on johdettu poikkileikkaussuureiden elementtiosuuksien kaavat lineaarisen kolmioelementin tapauksessa, kun kimmomoduuli $E^{e}$ ja liukumoduuli $G^{e}$ ovat vakioita elementin alueella. Seuraavassa esitetään nämä tulokset.

Aksiaalijäykkyyden $E A$ ja kimmomoduulilla painotettujen staattisten momenttien $E S_{z}$ ja $E S_{y}$ elementtiosuudet ovat

$$
(E A)^{e}=E^{e} A^{e}, \quad\left(E S_{z}\right)^{e}=E^{e} A^{e} \bar{y}^{e}, \quad\left(E S_{y}\right)^{e}=E^{e} A^{e} \bar{z}^{e} .
$$

Kimmomoduulilla painotettujen jäyhyysmomenttien $E I_{z}$ ja $E I_{y}$ sekä tulomomentin $E I_{y z}$ elementtiosuudet ovat

$$
\begin{aligned}
& \left(E I_{z}\right)^{e}=\frac{E^{e} A^{e}}{6}\left(y_{1}^{e} y_{1}^{e}+y_{2}^{e} y_{2}^{e}+y_{3}^{e} y_{3}^{e}+y_{2}^{e} y_{3}^{e}+y_{3}^{e} y_{1}^{e}+y_{1}^{e} y_{2}^{e}\right), \\
& \left(E I_{y}\right)^{e}=\frac{E^{e} A^{e}}{6}\left(z_{1}^{e} z_{1}^{e}+z_{2}^{e} z_{2}^{e}+z_{3}^{e} z_{3}^{e}+z_{2}^{e} z_{3}^{e}+z_{3}^{e} z_{1}^{e}+z_{1}^{e} z_{2}^{e}\right), \\
& \left(E I_{y z}\right)^{e}=\frac{E^{e} A^{e}}{12}\left(2 y_{1}^{e} z_{1}^{e}+2 y_{2}^{e} z_{2}^{e}+2 y_{3}^{e} z_{3}^{e}+y_{2}^{e} z_{3}^{e}+y_{3}^{e} z_{2}^{e}+y_{3}^{e} z_{1}^{e}+y_{1}^{e} z_{3}^{e}+y_{1}^{e} z_{2}^{e}+y_{2}^{e} z_{1}^{e}\right) .
\end{aligned}
$$

Suureiden $E S_{\Phi}, E I_{z \Phi}$ ja $E I_{y \Phi}$ elementtiosuudet ovat

$$
\begin{aligned}
& \left(E S_{\Phi}\right)^{e}=E^{e} A^{e} \bar{\Phi}^{e}, \\
& \begin{aligned}
\left(E I_{z \Phi}\right)^{e}=\frac{E^{e} A^{e}}{12} & \left(2 y_{1}^{e} \Phi_{1}^{e}+2 y_{2}^{e} \Phi_{2}^{e}+2 y_{3}^{e} \Phi_{3}^{e}\right. \\
& \left.+y_{2}^{e} \Phi_{3}^{e}+y_{3}^{e} \Phi_{2}^{e}+y_{3}^{e} \Phi_{1}^{e}+y_{1}^{e} \Phi_{3}^{e}+y_{1}^{e} \Phi_{2}^{e}+y_{2}^{e} \Phi_{1}^{e}\right), \\
\left(E I_{y \Phi}\right)^{e}=\frac{E^{e} A^{e}}{12} & \left(2 z_{1}^{e} \Phi_{1}^{e}+2 z_{2}^{e} \Phi_{2}^{e}+2 z_{3}^{e} \Phi_{3}^{e}\right. \\
& \left.+z_{2}^{e} \Phi_{3}^{e}+z_{3}^{e} \Phi_{2}^{e}+z_{3}^{e} \Phi_{1}^{e}+z_{1}^{e} \Phi_{3}^{e}+z_{1}^{e} \Phi_{2}^{e}+z_{2}^{e} \Phi_{1}^{e}\right),
\end{aligned}
\end{aligned}
$$

missä $\Phi_{i}^{e}$ ovat käyristymisfunktion $\Phi$ elementtisolmuarvot ja 


$$
\bar{\Phi}^{e}=\frac{\Phi_{1}^{e}+\Phi_{2}^{e}+\Phi_{3}^{e}}{3}
$$

Leikkausjäykkyyden $G A$, vääntöjäykkyyden $G J$ ja käyristymisjäykkyyden $E I_{\phi}$ elementtiosuudet ovat

$$
(G A)^{e}=G^{e} A^{e}
$$

$$
\begin{aligned}
(G J)^{e} & =\frac{G^{e} A^{e}}{6}\left[-3\left(b_{1} \Phi_{1}^{e}+b_{2} \Phi_{2}^{e}+b_{3} \Phi_{3}^{e}\right) \bar{z}^{e}+3\left(c_{1} \Phi_{1}^{e}+c_{2} \Phi_{2}^{e}+c_{3} \Phi_{3}^{e}\right) \bar{y}^{e}+y_{1}^{e} y_{1}^{e}\right. \\
& \left.+y_{2}^{e} y_{2}^{e}+y_{3}^{e} y_{3}^{e}+y_{2}^{e} y_{3}^{e}+y_{3}^{e} y_{1}^{e}+y_{1}^{e} y_{2}^{e}+z_{1}^{e} z_{1}^{e}+z_{2}^{e} z_{2}^{e}+z_{3}^{e} z_{3}^{e}+z_{2}^{e} z_{3}^{e}+z_{3}^{e} z_{1}^{e}+z_{1}^{e} z_{2}^{e}\right]
\end{aligned}
$$
ja

$$
\left(E I_{\phi}\right)^{e}=\frac{E^{e} A^{e}}{6}\left(\phi_{1}^{e} \phi_{1}^{e}+\phi_{2}^{e} \phi_{2}^{e}+\phi_{3}^{e} \phi_{3}^{e}+\phi_{2}^{e} \phi_{3}^{e}+\phi_{3}^{e} \phi_{1}^{e}+\phi_{1}^{e} \phi_{2}^{e}\right) .
$$

Suureiden $E I_{y \Psi_{y}}, E I_{z \Psi_{y}}, E I_{y \Psi_{z}}$ ja $E I_{z \Psi_{z}}$ elementtiosuudet ovat

$$
\begin{aligned}
&\left(E I_{y \Psi_{y}}\right)^{e}=\frac{E^{e} A^{e}}{12}\left(2 z_{1}^{e} \Psi_{y 1}^{e}+2 z_{2}^{e} \Psi_{y 2}^{e}+2 z_{3}^{e} \Psi_{y 3}^{e}\right. \\
&\left.+z_{2}^{e} \Psi_{y 3}^{e}+z_{3}^{e} \Psi_{y 2}^{e}+z_{3}^{e} \Psi_{y 1}^{e}+z_{1}^{e} \Psi_{y 3}^{e}+z_{1}^{e} \Psi_{y 2}^{e}+z_{2}^{e} \Psi_{y 1}^{e}\right), \\
&\left(E I_{z \Psi_{y}}\right)^{e}=\frac{E^{e} A^{e}}{12}\left(2 y_{1}^{e} \Psi_{y 1}^{e}+2 y_{2}^{e} \Psi_{y 2}^{e}+2 y_{3}^{e} \Psi_{y 3}^{e}\right.\left.+y_{2}^{e} \Psi_{y 3}^{e}+y_{3}^{e} \Psi_{y 2}^{e}+y_{3}^{e} \Psi_{y 1}^{e}+y_{1}^{e} \Psi_{y 3}^{e}+y_{1}^{e} \Psi_{y 2}^{e}+y_{2}^{e} \Psi_{y 1}^{e}\right), \\
&\left(E I_{y \Psi_{z}}\right)^{e}=\frac{E^{e} A^{e}}{12}\left(2 z_{1}^{e} \Psi_{z 1}^{e}+2 z_{2}^{e} \Psi_{z 2}^{e}+2 z_{3}^{e} \Psi_{z 3}^{e}\right. \\
&\left.\quad+z_{2}^{e} \Psi_{z 3}^{e}+z_{3}^{e} \Psi_{z 2}^{e}+z_{3}^{e} \Psi_{z 1}^{e}+z_{1}^{e} \Psi_{z 3}^{e}+z_{1}^{e} \Psi_{z 2}^{e}+z_{2}^{e} \Psi_{z 1}^{e}\right), \\
&\left(E I_{z \Psi_{z}}\right)^{e}=\frac{E^{e} A^{e}}{12}\left(2 y_{1}^{e} \Psi_{z 1}^{e}+2 y_{2}^{e} \Psi_{z 2}^{e}+2 y_{3}^{e} \Psi_{z 3}^{e}\right. \\
&\left.+y_{2}^{e} \Psi_{z 3}^{e}+y_{3}^{e} \Psi_{z 2}^{e}+y_{3}^{e} \Psi_{z 1}^{e}+y_{1}^{e} \Psi_{z 3}^{e}+y_{1}^{e} \Psi_{z 2}^{e}+y_{2}^{e} \Psi_{z 1}^{e}\right),
\end{aligned}
$$

missä $\Psi_{y i}^{e}$ ja $\Psi_{z i}^{e}$ ovat käyristymisfunktioiden $\Psi_{y}$ ja $\Psi_{z}$ elementtisolmuarvot.

\section{Palkkitehtävän analyyttinen ratkaisu}

Artikkelin osassa I kävi ilmi, että pakkitehtävässä veto/puristustehtävä, taivutustehtävä ja vääntötehtävä voidaan ratkaista erikseen. Syntyneet differentiaaliyhtälöt (I-79a), (I-83) ja (I-79d) ovat myös niin yksinkertaisia, että ne voidaan ratkaista analyyttisesti. Tässä analyyttistä ratkaisua tarkastellaan hieman yksityiskohtaisemmin.

\section{Veto/puristustehtävä}

Veto/puristustehtävässä aksiaalisen siirtymän differentiaaliyhtälö (I-79a) on

$$
u^{\prime \prime}(x)=-\frac{q_{x}(x)}{E A}
$$


ja normaalivoiman ja aksiaalisen siirtymän yhteys (I-54a) on

$$
N(x)=E A u^{\prime}(x) \text {. }
$$

Differentiaaliyhtälön (32) ratkaisu on

$$
u(x)=C_{1} x+C_{2}+u_{0}(x),
$$

missä $u_{0}(x)$ on yksityisratkaisu. Tiettyä jakautunutta aksiaalista kuormaa $q_{x}(x)$ vastaava yksityisratkaisu saadaan integroimalla täydellinen yhtälö (32) puolittain kahdesti ja jättämällä integrointivakiot pois. Kun yksityisratkaisu $u_{0}(x)$ tunnetaan, voidaan huomioimalla reunaehdot palkin päissä ja soveltamalla yhtälöitä (33) ja (34) määrittää veto/puristustehtävän analyyttinen ratkaisu.

Määritetään esimerkkinä yksityisratkaisu $u_{0}(x)$ siinä tapauksessa, että aksiaalinen kuorma jakautuu lineaarisesti, jolloin se voidaan esittää muodossa

$$
q_{x}(x)=q_{x 1}+\frac{q_{x 2}-q_{x 1}}{L} x,
$$

missä $q_{x 1}$ ja $q_{x 2}$ ovat kuorman arvot palkin päissä ja $L$ on palkin pituus. Sijoittamalla tämä yhtälöön (32) ja integroimalla se puolittain kahdesti saadaan yksityisratkaisuksi

$$
u_{0}(x)=-\frac{1}{2} \frac{q_{x 1}}{E A} x^{2}-\frac{1}{6} \frac{q_{x 2}-q_{x 1}}{E A L} x^{3} .
$$

Useimmissa käytännön tehtävissä aksiaalinen jakautunut kuorma on nolla, vakio tai lineaarinen, jolloin tämä tulos on sovellettavissa.

\section{Taivutustehtävä}

Palkin taivutukseen liittyville siirtymäsuureille ja jännitysresultanteille käytetään tässä seuraavia merkintöjä

$$
\mathbf{v}=\left\{\begin{array}{c}
v \\
w
\end{array}\right\}, \quad \boldsymbol{\Theta}=\left\{\begin{array}{c}
\theta_{z} \\
\theta_{y}
\end{array}\right\}, \quad \gamma=\left\{\begin{array}{c}
\gamma_{y} \\
\gamma_{z}
\end{array}\right\}, \quad \mathbf{M}=\left\{\begin{array}{l}
M_{z} \\
M_{y}
\end{array}\right\}, \quad \mathbf{Q}=\left\{\begin{array}{l}
Q_{y} \\
Q_{z}
\end{array}\right\}
$$

ja kutsutaan vastaavasti taipuma-, kiertymä-, liukuma-, taivutusmomentti- ja leikkausvoimavektoreiksi. Jakautuneille kuormille käytetään merkintöjä

$$
\mathbf{q}=\left\{\begin{array}{l}
q_{y} \\
q_{z}
\end{array}\right\}, \quad \mathbf{m}=\left\{\begin{array}{l}
m_{z} \\
m_{y}
\end{array}\right\}
$$

ja kutsutaan poikittaiskuorma- ja momenttikuormavektoreiksi. Taivutusjäykkyyksistä (B bending) ja leikkausjäykkyyksistä (S shear) muodostetaan myös matriisit

$$
\mathbf{B}=\left[\begin{array}{cc}
E I_{z} & E I_{y z} \\
E I_{y z} & E I_{y}
\end{array}\right], \quad \mathbf{S}=G A\left[\begin{array}{cc}
k_{y} & k_{y z} \\
k_{y z} & k_{z}
\end{array}\right] .
$$

Tarkastellaan tässä taivutustehtävää näitä merkintöjä käyttäen. Palkin tasapainoyhtälöt (I44d), (I-44e), (I-44b) ja (I-44c) ovat

$$
\mathbf{Q}^{\prime}+\mathbf{q}=\mathbf{0}
$$

ja

$$
\mathbf{Q}=\mathbf{M}^{\prime}+\mathbf{m} .
$$

Keskimääräisten liukumien, taipumien ja poikkileikkauksen kiertymien yhteydet (I-14) ovat 


$$
\boldsymbol{\gamma}=\mathbf{v}^{\prime}-\Theta,
$$

taivutusmomenttien ja poikkileikkauksen kiertymien yhteydet (I-54b) ovat

$$
\mathbf{M}=-\mathbf{B} \Theta^{\prime}
$$

ja leikkausvoimien ja keskimääräisten liukumien yhteydet (I-60) ovat

$$
\mathbf{Q}=\mathbf{S} \boldsymbol{\gamma} \text {. }
$$

Poikkileikkauksen kiertymille saadaan kaavoilla (42) ja (44)

$$
\Theta=\mathbf{v}^{\prime}-\mathbf{S}^{-1} \mathbf{Q}
$$

taivutusmomenteille kaavoilla (43), (45) ja (40)

$$
\mathbf{M}=-\mathbf{B}\left(\mathbf{v}^{\prime \prime}+\mathbf{S}^{-1} \mathbf{q}\right)
$$

ja leikkausvoimille saadaan kaavoilla (41) ja (46)

$$
\mathbf{Q}=-\mathbf{B}\left(\mathbf{v}^{\prime \prime \prime}+\mathbf{S}^{-1} \mathbf{q}^{\prime}\right)+\mathbf{m} .
$$

Poikkileikkauksen kiertymille saadaan kaavoilla (45) ja (47)

$$
\boldsymbol{\Theta}=\mathbf{v}^{\prime}+\mathbf{S}^{-1} \mathbf{B} \mathbf{v}^{\prime \prime \prime}+\mathbf{S}^{-1} \mathbf{B S} \mathbf{q}^{-1} \mathbf{q}^{\prime}-\mathbf{S}^{-1} \mathbf{m} \text {. }
$$

Sijoittamalla leikkausvoimat (47) tasapainoyhtälöön (40) saadaan palkin taipumille $\mathbf{v}(x)$ differentiaaliyhtälö

$$
\mathbf{v}^{(4)}=\mathbf{B}^{-1}\left(\mathbf{q}+\mathbf{m}^{\prime}\right)-\mathbf{S}^{-1} \mathbf{q}^{\prime \prime} .
$$

Tämä on yhtälö (I-81) matriisimuotoisena. Yhtälön (49) yleinen ratkaisu on

$$
\mathbf{v}(x)=\frac{x^{3}}{6} \mathbf{C}_{1}+\frac{x^{2}}{2} \mathbf{C}_{2}+x \mathbf{C}_{3}+\mathbf{C}_{4}+\mathbf{v}_{0}(x),
$$

missä $\mathbf{C}_{i}, i=1,2,3,4$, ovat integrointivakioista kootut $2 \times 1$ pystyvektorit ja $\mathbf{v}_{0}(x)$ on yksityisratkaisu. Tiettyjä jakautuneita kuormituksia $\mathbf{q}(x)$ ja $\mathbf{m}(x)$ vastaava yksityisratkaisu saadaan integroimalla täydellinen yhtälö (49) puolittain neljästi ja jättämällä integrointivakiot pois. Kun yksityisratkaisu $\mathbf{v}_{0}(x)$ tunnetaan, voidaan huomioimalla reunaehdot palkin päissä ja soveltamalla yhtälöitä (46), (47), (48) ja (50) määrittää taivutustehtävän analyyttinen ratkaisu.

Määritetään esimerkkinä yksityisratkaisu $\mathbf{v}_{0}(x)$ siinä tapauksessa, että poikittainen kuorma ja momenttikuorma jakautuvat lineaarisesti, jolloin ne voidaan esittää muodossa

$$
\mathbf{q}(x)=\mathbf{q}_{1}+\frac{1}{L}\left(\mathbf{q}_{2}-\mathbf{q}_{1}\right) x, \quad \mathbf{m}(x)=\mathbf{m}_{1}+\frac{1}{L}\left(\mathbf{m}_{2}-\mathbf{m}_{1}\right) x,
$$

missä $\mathbf{q}_{1}, \mathbf{q}_{2}, \mathbf{m}_{1}$ ja $\mathbf{m}_{2}$ ovat kuormien arvot palkin päissä yhtälö (49) saa muodon

$$
\mathbf{v}^{(4)}=\mathbf{B}^{-1}\left[\mathbf{q}_{1}+\frac{1}{L}\left(\mathbf{q}_{2}-\mathbf{q}_{1}\right) x+\frac{1}{L}\left(\mathbf{m}_{2}-\mathbf{m}_{1}\right)\right] .
$$

Integroimalla tämä puolittain neljästi ja jättämällä integrointivakiot pois saadaan yksityisratkaisuksi tulos

$$
\mathbf{v}_{0}(x)=\mathbf{B}^{-1}\left[\frac{x^{4}}{24} \mathbf{q}_{1}+\frac{x^{5}}{120 L}\left(\mathbf{q}_{2}-\mathbf{q}_{1}\right)+\frac{x^{4}}{24 L}\left(\mathbf{m}_{2}-\mathbf{m}_{1}\right)\right] .
$$

Useimmissa käytännön tehtävissä jakautunut poikittainen kuorma ja momenttikuorma ovat korkeintaan lineaarisia, jolloin tämä tulos on sovellettavissa. 


\section{Vääntötehtävä}

Vääntökulman $\theta_{x}(x)$ differentiaaliyhtälö (I-79d) on

$$
\theta_{x}^{(4)}-\left(\frac{k}{L}\right)^{2} \theta_{x}^{\prime \prime}=\frac{m_{x}+b^{\prime}}{E I_{\phi}}
$$

missä

$$
k=L \sqrt{\frac{G J}{E I_{\phi}}},
$$

ja $L$ on palkin pituus. Saint-Venantin vääntömomentin, käyristymismomentin ja kokonaisvääntömomentin lausekkeet (I-76), (I-54c) ja (I-77) ovat

$$
\begin{gathered}
T(x)=G J \theta_{x}^{\prime}(x), \\
B(x)=-E I_{\phi} \theta_{x}^{\prime \prime}(x)
\end{gathered}
$$

ja

$$
M_{x}(x)=B^{\prime}(x)+T(x)=-E I_{\phi} \theta_{x}^{\prime \prime \prime}(x)+G J \theta_{x}^{\prime}(x) .
$$

Differentiaaliyhtälön (54) yleinen ratkaisu on

$$
\theta_{x}(x)=C_{1}+C_{2} x+C_{3} \sinh \left(\frac{k}{L} x\right)+C_{4} \cosh \left(\frac{k}{L} x\right)+\theta_{x 0}(x)
$$

missä $\theta_{x 0}(x)$ on jakautuneita kuormituksia $m_{x}(x)$ ja $b(x)$ vastaava yksityisratkaisu. Kun yksityisratkaisu $\theta_{x 0}(x)$ tunnetaan, voidaan huomioimalla reunaehdot ja soveltamalla yhtälöitä (56)-(59) määrittää vääntötehtävän analyyttinen ratkaisu.

Määritetään esimerkkinä yksityisratkaisu $\theta_{x 0}(x)$ siinä tapauksessa, että momenttikuorma ja käyristymismomenttikuorma jakautuvat lineaarisesti, jolloin ne voidaan esittää muodossa

$$
m_{x}(x)=m_{x 1}+\frac{m_{x 2}-m_{x 1}}{L} x, \quad b(x)=b_{1}+\frac{b_{2}-b_{1}}{L} x,
$$

missä $m_{x 1}, m_{x 2}, b_{1}$ ja $b_{2}$ ovat kuormien arvot palkin päissä. Käytetään yritettä

$$
\theta_{x}(x)=\alpha x^{2}+\beta x^{3}
$$

missä $\alpha$ ja $\beta$ ovat vakioita. Sijoittamalla se differentiaaliyhtälöön (54) saadaan yhtälö

$$
-2 \alpha-6 \beta x=\frac{1}{G J}\left(m_{x 1}+\frac{b_{2}-b_{1}}{L}\right)+\frac{m_{x 2}-m_{x 1}}{G J L} x
$$

josta seuraa vakioille

$$
\alpha=-\frac{1}{2} \frac{1}{G J}\left(m_{x 1}+\frac{b_{2}-b_{1}}{L}\right), \quad \beta=-\frac{1}{6} \frac{m_{x 2}-m_{x 1}}{G J L} .
$$

Yksityisratkaisulle saadaan siis tulos

$$
\theta_{x 0}(x)=-\frac{1}{2} \frac{m_{x 1}}{G J} x^{2}-\frac{1}{6} \frac{m_{x 2}-m_{x 1}}{G J L} x^{3}-\frac{1}{2} \frac{b_{2}-b_{1}}{G J L} x^{2} .
$$

Useimmissa käytännön tehtävissä jakautunut vääntävä momenttikuorma ja käyristymismomenttikuorma ovat korkeintaan lineaarisia, jolloin tämä tulos on sovellettavissa. Myös monimutkaisemmin jakautuneiden kuormien $m_{x}(x)$ ja $b(x)$ tapauksessa yksityisratkaisu 
on löydettävissä. Koska differentiaaliyhtälö (54) on analoginen ohutseinämäisten avointen poikkileikkausten vääntöteoriassa esiintyvän vastaavan yhtälön kanssa, voidaan alan kirjallusuudessa esitettyjä yksityisratkaisuja myös hyödyntää. Esimerkiksi lähteen [3] sivuilla 162-163 on esitetty joitain yksityisratkaisuja.

\section{Palkkitehtävän analyyttisiin ratkaisuihin perustuva elementtiratkaisu}

Palkkitehtävän analyyttisten ratkaisujen määrittäminen monimutkaisemmissa tapauksissa on työlästä, joten prosessi on tarkoituksenmukaista systematisoida käyttäen elementtimenetelmän tekniikkaa. Seuraavassa esitellään elementit, joiden avulla veto/puristus-, taivutus- ja vääntötehtävät voidaan ratkaista. Tässä esitetään elementtien jäykkyysmatriisit ja kuormitusvektorit siinä tapauksessa, että elementtiin kohdistuva kuormitus on lineaarisesti jakautunut. Johdot on esitetty liitteissä C, D ja E. Niissä on myös esitetty, kuinka siirtymäsuureiden ja jännitysresultanttien tarkat jakaumat elementtien alueella voidaan määrittää. Tehtävät voisi myös formuloida likimääräisesti virtuaalisen työn periaatetta ja tavanomaisia $C^{0}$ - ja $C^{1}$-jatkuvia janaelementtejä käyttäen, mutta tässä pitäydytään menettelyyn, joka antaa kaikille osatehtäville analyyttiset ratkaisut.

\section{Veto/puristustehtävä}

Liitteessä C on johdettu veto/puristustehtävän elementtiratkaisu. Elementin jäykkyysmatriisille saatiin

$$
\mathbf{K}^{e}=\frac{E A}{L^{e}}\left[\begin{array}{cc}
1 & -1 \\
-1 & 1
\end{array}\right]
$$

missä $E A$ on elementin aksiaalinen jäykkyys ja $L^{e}$ on elementin pituus. Siinä tapauksessa, että aksiaalinen kuorma $q_{x}(x)$ jakautuu elementin alueella lineaarisesti, elementin kuormitusvektorille saatiin

$$
\mathbf{R}^{e}=\frac{q_{x 1}^{e} L^{e}}{6}\left\{\begin{array}{l}
2 \\
1
\end{array}\right\}+\frac{q_{x 2}^{e} L^{e}}{6}\left\{\begin{array}{l}
1 \\
2
\end{array}\right\},
$$

missä $q_{x 1}^{e} q_{x 2}^{e}$ ovat kuorman arvot elementin päissä. Liitteessä C on myös esitetty, kuinka elementin kuormitusvektori saadaan monimutkaisemmin jakautuneen kuorman $q_{x}(x)$ tapauksessa sekä kuinka aksiaalisen siirtymän $u(x)$ ja normaalivoiman $N(x)$ tarkka jakautuminen elementin alueella voidaan määrittää.

\section{Taivutustehtävä}

Liitteessä D on johdettu taivutustehtävän elementtiratkaisu. Elementin jäykkyys-matriisille saatiin 
missä

$$
\mathbf{K}^{e}=\mathbf{B}(\mathbf{I}+\varphi)^{-1}\left[\begin{array}{cccc}
\frac{12}{L^{e 3}} \mathbf{I} & \frac{6}{L^{22}} \mathbf{I} & -\frac{12}{L^{e 3}} \mathbf{I} & \frac{6}{L^{e 2}} \mathbf{I} \\
\frac{6}{L^{e 2}} \mathbf{I} & \frac{1}{L^{e}}(4 \mathbf{I}+\varphi) & -\frac{6}{L^{e 2}} \mathbf{I} & \frac{1}{L^{e}}(2 \mathbf{I}-\varphi) \\
-\frac{12}{L^{e 3}} \mathbf{I} & -\frac{6}{L^{e 2}} \mathbf{I} & \frac{12}{L^{e 3}} \mathbf{I} & -\frac{6}{L^{e 2}} \mathbf{I} \\
\frac{6}{L^{e 2}} \mathbf{I} & \frac{1}{L^{e}}(2 \mathbf{I}-\varphi) & -\frac{6}{L^{e 2}} \mathbf{I} & \frac{1}{L^{e}}(4 \mathbf{I}+\varphi)
\end{array}\right]
$$

$$
\varphi=\frac{12}{L^{e 2}} \mathbf{S}^{-1} \mathbf{B}
$$

I on $2 \times 2$ yksikkömatriisi ja $L^{e}$ on elementin pituus. Siinä tapauksessa, että jakautunut poikittainen kuorma $\mathbf{q}(x)$ ja momenttikuorma $\mathbf{m}(x)$ jakautuvat elementin alueella lineaarisesti, elementin kuormitusvektorille saatiin

$$
\mathbf{R}^{e}=(\mathbf{I}+\boldsymbol{\varphi})^{-1}\left[\left[\begin{array}{c}
\frac{7 L^{e}}{20} \mathbf{I}+\frac{L^{e}}{3} \boldsymbol{\varphi} \\
\frac{L^{e 2}}{20} \mathbf{I}+\frac{L^{e 2}}{24} \boldsymbol{\varphi} \\
\frac{3 L^{e}}{20} \mathbf{I}+\frac{L^{e}}{6} \boldsymbol{\varphi} \\
-\frac{L^{e 2}}{30} \mathbf{I}-\frac{L^{e 2}}{24} \boldsymbol{\varphi}
\end{array}\right] \mathbf{q}_{1}^{e}+\left[\begin{array}{c}
\frac{3 L^{e}}{20} \mathbf{I}+\frac{L^{e}}{6} \boldsymbol{\varphi} \\
\frac{L^{e 2}}{30} \mathbf{I}+\frac{L^{e 2}}{24} \boldsymbol{\varphi} \\
\frac{7 L^{e}}{20} \mathbf{I}+\frac{L^{e}}{3} \boldsymbol{\varphi} \\
-\frac{L^{e 2}}{20} \mathbf{I}-\frac{L^{e 2}}{24} \boldsymbol{\varphi}
\end{array}\right] \mathbf{q}_{2}^{e}\right]+\left[\begin{array}{c}
\frac{1}{2} \mathbf{I} \\
-\frac{L^{e}}{12}(\mathbf{I}-\boldsymbol{\varphi}) \\
-\frac{1}{2} \mathbf{I} \\
\frac{L^{e}}{12}(\mathbf{I}-\boldsymbol{\varphi})
\end{array}\right] \mathbf{m}_{1}^{e}+\left[\begin{array}{c}
\frac{1}{2} \mathbf{I} \\
\frac{L^{e}}{12}(\mathbf{I}-\boldsymbol{\varphi}) \\
-\frac{1}{2} \mathbf{I} \\
-\frac{L^{e}}{12}(\mathbf{I}-\boldsymbol{\varphi})
\end{array}\right] \mathbf{m}_{2}^{e},
$$

missä $\mathbf{q}_{1}^{e}, \mathbf{q}_{2}^{e}, \mathbf{m}_{1}^{e}$ ja $\mathbf{m}_{2}^{e}$ ovat kuormien arvot elementin päissä. Liitteessä D on myös esitetty, kuinka elementin kuormitusvektori saadaan monimutkaisemmin jakautuneiden kuormien $\mathbf{q}(x)$ ja $\mathbf{m}(x)$ tapauksessa sekä kuinka taipumien $\mathbf{v}(x)$, poikkileikkauksen kiertymien $\Theta(x)$, leikkausvoimien $\mathbf{Q}(x)$ ja taivutusmomenttien $\mathbf{M}(x)$ tarkka jakautu-minen elementin alueella voidaan määrittää.

Elementti, jonka jäykkyysmatriisi on kaavan (67) mukainen, soveltuu taivutustehtävän ratkaisemiseen yleisessä tapauksessa. Liitteessä D on esitetty, että symmetrisen poikkileikkauksen tapauksessa, jos $y$ - tai $z$-akseli yhtyy poikkileikkauksen symmetria-akseliin, kytkentä $(x, y)$ - ja $(x, z)$-tasoissa tapahtuvan taivutuksen välillä häviää. Tällöin tässä esitetyt yhtälöt yhtyvät lähteessä [2] esitetyn elementin yhtälöihin.

\section{Vääntötehtävä}

Liitteessä E on johdettu vääntötehtävän elementtiratkaisu. Elementin jäykkyysmatriisille saatiin 


$$
\mathbf{K}^{e}=\frac{G J}{2+k \operatorname{sh}-2 \mathrm{ch}}\left[\begin{array}{cccc}
\frac{k}{L^{e}} \mathrm{sh} & \mathrm{ch}-1 & -\frac{k}{L^{e}} \mathrm{sh} & \mathrm{ch}-1 \\
\operatorname{ch}-1 & \frac{L^{e}}{k}(k \mathrm{ch}-\mathrm{sh}) & 1-\mathrm{ch} & \frac{L^{e}}{k}(\mathrm{sh}-k) \\
-\frac{k}{L^{e}} \mathrm{sh} & 1-\mathrm{ch} & \frac{k}{L^{e}} \mathrm{sh} & 1-\mathrm{ch} \\
\operatorname{ch}-1 & \frac{L^{e}}{k}(\mathrm{sh}-k) & 1-\mathrm{ch} & \frac{L^{e}}{k}(k \mathrm{ch}-\mathrm{sh})
\end{array}\right],
$$

missä

$$
k=L^{e} \sqrt{\frac{G J}{E I_{\phi}}},
$$

$G J$ on elementin Saint-Venantin vääntöjäykkyys, $E I_{\phi}$ on elementin käyristymisjäykkyys ja $L^{e}$ on elementin pituus. Kaavassa (70) käytetään myös lyhennysmerkintöjä $\operatorname{sh}=\sinh (k)$ ja ch $=\cosh (k)$. Siinä tapauksessa, että jakautunut momenttikuorma $m_{x}(x)$ ja käyristymismomenttikuorma $b(x)$ jakautuvat elementin alueella lineaarisesti kuormitusvektorille saatiin

$$
\begin{aligned}
& \mathbf{R}^{e}=\frac{1}{2+k \mathrm{sh}-2 \mathrm{ch}} \\
& {\left[\begin{array}{c}
\left(\frac{k^{2}-4}{2 k^{2}}+\frac{k^{2}-3}{3 k} \mathrm{sh}-\frac{k^{2}-4}{2 k^{2}} \mathrm{ch}\right) L^{e} \\
\left.6 k^{2}-\frac{k^{2}-12}{2 k} \mathrm{sh}+\frac{k^{2}+6}{3 k^{2}} \mathrm{ch}\right) L^{e 2} \\
\left(\frac{k^{2}+4}{2 k^{2}}+\frac{k^{2}+6}{6 k} \mathrm{sh}-\frac{k^{2}+4}{2 k^{2}} \mathrm{ch}\right) L^{e} \\
\left(-\frac{1}{3}+\frac{1}{2 k} \mathrm{sh}-\frac{1}{6} \mathrm{ch}\right) L^{e 2}
\end{array}\right\} m_{x 1}^{e}+\left\{\begin{array}{c}
\left(\frac{k^{2}+4}{2 k^{2}}+\frac{k^{2}+6}{6 k} \mathrm{sh}-\frac{k^{2}+4}{2 k^{2}} \mathrm{ch}\right) L^{e} \\
\left(\frac{1}{3}-\frac{1}{2 k} \mathrm{sh}+\frac{1}{6} \mathrm{ch}\right) L^{e 2} \\
\left(\frac{k^{2}-4}{2 k^{2}}+\frac{k^{2}-3}{3 k} \mathrm{sh}-\frac{k^{2}-4}{2 k^{2}} \mathrm{ch}\right) L^{e} \\
-\left(\frac{k^{2}-12}{6 k^{2}}-\frac{3}{2 k} \mathrm{sh}+\frac{k^{2}+6}{3 k^{2}} \mathrm{ch}\right) L^{e 2}
\end{array}\right\} m_{x 2}^{e}} \\
& \left.+\left\{\begin{array}{c}
1+\frac{k}{2} \mathrm{sh}-\mathrm{ch} \\
\left(\frac{k^{2}-4}{2 k^{2}}-\frac{2}{k} \mathrm{sh}+\frac{k^{2}+4}{2 k^{2}} \mathrm{ch}\right) L^{e} \\
1+\frac{k}{2} \mathrm{sh}-\mathrm{ch} \\
-\left(\frac{k^{2}-4}{2 k^{2}}-\frac{2}{k} \mathrm{sh}+\frac{k^{2}+4}{2 k^{2}} \mathrm{ch}\right) L^{e}
\end{array}\right\}\left(b_{2}^{e}-b_{1}^{e}\right)\right]
\end{aligned}
$$

missä $m_{x 1}^{e}, m_{x 2}^{e}, b_{1}^{e}$ ja $b_{2}^{e}$ ovat kuormien arvot elementin päissä. Liitteessä E on myös esitetty, kuinka elementin kuormitusvektori saadaan monimutkaisemmin jakautuneiden kuormien $m_{x}(x)$ ja $b(x)$ tapauksessa sekä kuinka vääntökulman $\theta_{x}(x)$, Saint-Venantin vääntömomentin $T(x)$, käyristymismomentin $B(x)$ ja kokonaisvääntömomentin $M_{x}(x)$ 
tarkka jakautuminen elementin alueella voidaan määrittää.

\section{Poikkileikkauksen jännitysjakautuman määrittäminen}

\section{Poikkileikkauksen jännityskomponenttien jakautuminen}

Kun palkin poikkileikkauksen käyristymisfunktiot $\phi(y, z), \Phi(y, z), \Psi_{x}(y, z), \Psi_{y}(y, z)$ ja $\Psi_{z}(y, z)$ on ratkaistu ja palkin jännitysresultantit $N, M_{y}, M_{z}, Q_{z}, Q_{y}, T, B$ ja derivaatta $B^{\prime}$ tarkasteltavassa poikkileikkauksessa $x=x_{0}$ tunnetaan, voidaan kaavojen (I87) perusteella tietyn poikkileikkauksen normaali ja leikkausjännitysjakaumat määrittää kaavoilla

$$
\sigma_{x}=\sigma_{x}^{\mathrm{s}}+\sigma_{x}^{\mathrm{b}}+\sigma_{x}^{\mathrm{t}}, \quad\left\{\begin{array}{c}
\tau_{y x} \\
\tau_{z x}
\end{array}\right\}=\left\{\begin{array}{c}
\tau_{y x}^{\mathrm{b}} \\
\tau_{z x}^{\mathrm{b}}
\end{array}\right\}+\left\{\begin{array}{c}
\tau_{y x}^{\mathrm{t}} \\
\tau_{z x}^{\mathrm{t}}
\end{array}\right\},
$$

missä yläindeksit $\mathrm{s}, \mathrm{b}$ ja t viittaavat veto/puristus- (stretching), taivutus- (bending) ja vääntötehtävään (twisting). Näitä vastaavat normaalijännitykset ovat

$$
\sigma_{x}^{\mathrm{s}}=E \frac{N}{E A}, \quad \sigma_{x}^{\mathrm{b}}=E\left\{\begin{array}{l}
M_{z} \\
M_{y}
\end{array}\right\}^{T}\left[\begin{array}{cc}
E I_{z} & E I_{y z} \\
E I_{y z} & E I_{y}
\end{array}\right]^{-1}\left\{\begin{array}{l}
y \\
z
\end{array}\right\}, \quad \sigma_{x}^{\mathrm{t}}=-E \frac{B}{E I_{\phi}} \phi
$$

ja leikkausjännitykset ovat

$$
\begin{aligned}
& \left\{\begin{array}{c}
\tau_{y x}^{\mathrm{b}} \\
\tau_{z x}^{\mathrm{b}}
\end{array}\right\}=G\left[\begin{array}{cc}
\frac{\partial \Psi_{y}}{\partial y} & \frac{\partial \Psi_{z}}{\partial y} \\
\frac{\partial \Psi_{y}}{\partial z} & \frac{\partial \Psi_{z}}{\partial z}
\end{array}\right]\left[\begin{array}{cc}
E I_{z} & E I_{y z} \\
E I_{y z} & E I_{y}
\end{array}\right]^{-1}\left\{\begin{array}{c}
Q_{y} \\
Q_{z}
\end{array}\right\}, \\
& \left\{\begin{array}{c}
\tau_{y x}^{\mathrm{t}} \\
\tau_{z x}^{\mathrm{t}}
\end{array}\right\}=G\left(\frac{T}{G J}\left\{\begin{array}{c}
\frac{\partial \Phi}{\partial y}-z \\
\frac{\partial \Phi}{\partial z}+y
\end{array}\right\}-\frac{B^{\prime}}{E I_{\phi}}\left\{\begin{array}{c}
\frac{\partial \Psi_{x}}{\partial y} \\
\frac{\partial \Psi_{x}}{\partial z}
\end{array}\right\}\right) .
\end{aligned}
$$

Artikkelin ensimmäisen osan kaavoista (I-87) poiketen on tässä siis vedon/puristuksen, taivutuksen ja väännön osuudet jännityksistä eritelty.

\section{Poikkileikkauksen jännityskentän määrittäminen lineaarisen} kolmioelementin tapauksessa

Jännitysten (74) ja (75) arvot elementin $e$ solmun $i$ kohdalla voidaan määrittää kaavoilla

$$
\begin{gathered}
\left(\sigma_{x}^{\mathrm{s}}\right)_{i}^{e}=E^{e} \frac{N}{E A}, \quad\left(\sigma_{x}^{\mathrm{b}}\right)_{i}^{e}=E^{e}\left\{\begin{array}{l}
M_{z} \\
M_{y}
\end{array}\right\}^{T}\left[\begin{array}{cc}
E I_{z} & E I_{y z} \\
E I_{y z} & E I_{y}
\end{array}\right]^{-1}\left\{\begin{array}{l}
y_{i}^{e} \\
z_{i}^{e}
\end{array}\right\}, \quad\left(\sigma_{x}^{\mathrm{t}}\right)_{i}^{e}=-E^{e} \frac{B}{E I_{\phi}} \phi_{i}^{e}, \\
\left\{\begin{array}{l}
\left(\tau_{y x}^{\mathrm{t}}\right)_{i}^{e} \\
\left(\tau_{z x}^{\mathrm{t}}\right)_{i}^{e}
\end{array}\right\}=G^{e}\left(\frac{T}{G J}\left\{\begin{array}{l}
\left(\frac{\partial \Phi}{\partial y}\right)^{e}-z_{i}^{e} \\
\left(\frac{\partial \Phi}{\partial z}\right)^{e}+y_{i}^{e}
\end{array}\right\}-\frac{B^{\prime}}{E I_{\phi}}\left\{\begin{array}{l}
\left(\frac{\partial \Psi_{x}}{\partial y}\right)^{e} \\
\left(\frac{\partial \Psi_{x}}{\partial z}\right)^{e}
\end{array}\right\}\right),
\end{gathered}
$$




$$
\left\{\begin{array}{l}
\left(\tau_{y x}^{\mathrm{b}}\right)_{i}^{e} \\
\left(\tau_{z x}^{\mathrm{b}}\right)_{i}^{e}
\end{array}\right\}=G^{e}\left[\begin{array}{cc}
\left(\frac{\partial \Psi_{y}}{\partial y}\right)^{e} & \left(\frac{\partial \Psi_{z}}{\partial y}\right)^{e} \\
\left(\frac{\partial \Psi_{y}}{\partial z}\right)^{e} & \left(\frac{\partial \Psi_{z}}{\partial z}\right)^{e}
\end{array}\right]\left[\begin{array}{cc}
E I_{z} & E I_{y z} \\
E I_{y z} & E I_{y}
\end{array}\right]^{-1}\left\{\begin{array}{l}
Q_{y} \\
Q_{z}
\end{array}\right\},
$$

missä $y_{i}^{e}$ ja $z_{i}^{e}$ ovat elementtisolmujen koordinaatit. Käyristymisfunktioiden osittaisderivaatat, jotka ovat vakioita elementin alueella, lasketaan kaavoilla

$$
\begin{aligned}
\left(\frac{\partial \Phi}{\partial y}\right)^{e}=\frac{1}{2 A^{e}}\left(b_{1} \Phi_{1}^{e}+b_{2} \Phi_{2}^{e}+b_{3} \Phi_{3}^{e}\right), & \left(\frac{\partial \Phi}{\partial z}\right)^{e}=\frac{1}{2 A^{e}}\left(c_{1} \Phi_{1}^{e}+c_{2} \Phi_{2}^{e}+c_{3} \Phi_{3}^{e}\right), \\
\left(\frac{\partial \Psi_{x}}{\partial y}\right)^{e}=\frac{1}{2 A^{e}}\left(b_{1} \Psi_{x 1}^{e}+b_{2} \Psi_{x 2}^{e}+b_{3} \Psi_{x 3}^{e}\right), & \left(\frac{\partial \Psi_{x}}{\partial z}\right)^{e}=\frac{1}{2 A^{e}}\left(c_{1} \Psi_{x 1}^{e}+c_{2} \Psi_{x 2}^{e}+c_{3} \Psi_{x 3}^{e}\right), \\
\left(\frac{\partial \Psi_{y}}{\partial y}\right)^{e}=\frac{1}{2 A^{e}}\left(b_{1} \Psi_{y 1}^{e}+b_{2} \Psi_{y 2}^{e}+b_{3} \Psi_{y 3}^{e}\right), & \left(\frac{\partial \Psi_{y}}{\partial z}\right)^{e}=\frac{1}{2 A^{e}}\left(c_{1} \Psi_{y 1}^{e}+c_{2} \Psi_{y 2}^{e}+c_{3} \Psi_{y 3}^{e}\right), \\
\left(\frac{\partial \Psi_{z}}{\partial y}\right)^{e}=\frac{1}{2 A^{e}}\left(b_{1} \Psi_{z 1}^{e}+b_{2} \Psi_{z 2}^{e}+b_{3} \Psi_{z 3}^{e}\right), & \left(\frac{\partial \Psi_{z}}{\partial z}\right)^{e}=\frac{1}{2 A^{e}}\left(c_{1} \Psi_{z 1}^{e}+c_{2} \Psi_{z 2}^{e}+c_{3} \Psi_{z 3}^{e}\right),
\end{aligned}
$$

missä $\Phi_{i}^{e}, \Psi_{x i}^{e}, \Psi_{y i}^{e}$ ja $\Psi_{z i}^{e} i=1,2,3$ ovat käyristymisfunktioiden $\Phi, \Psi_{x}, \Psi_{y}$ ja $\Psi_{z}$ elementtisolmuarvot.

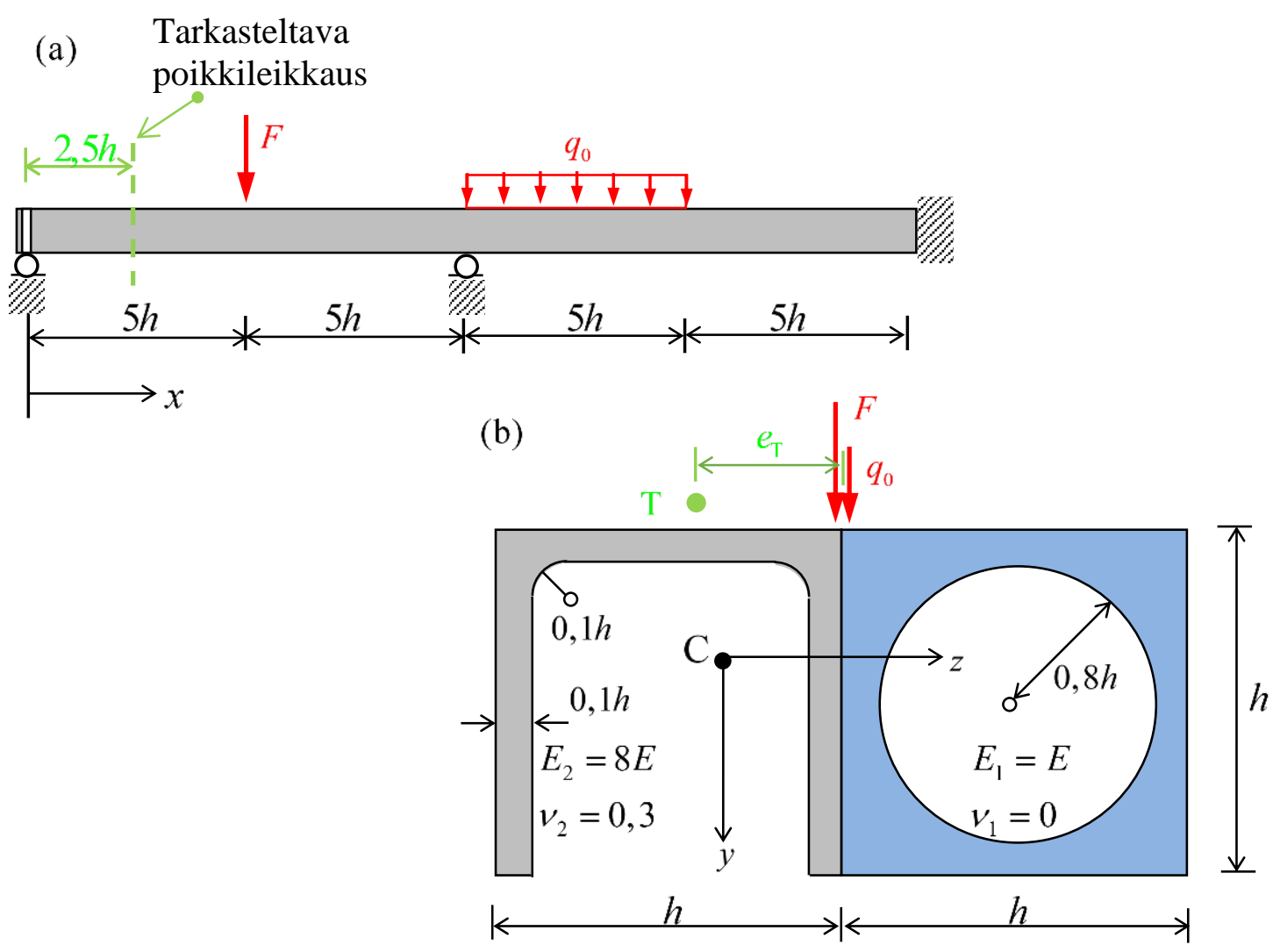

Kuva 1. (a) Kolmitukinen palkki ja (b) sen kahdesta materiaalista koostuva poikkileikkaus 


\section{Esimerkkitehtävä}

Tarkastellaan kuvan 1a kahdesta materiaalista koostuvaa kolmitukista palkkia, jota kuormittaa sen neljännespisteessä $x=5 h$ pistekuorma $F$ ja välillä $10 h<x<15 h$ tasan jakautunut viivakuorma $q_{0}=F /(5 h)$. Vasemmasta päästään $x=0$ palkki on tuettu siten, että sen siirtyminen akselia vastaan kohtisuorassa tasossa ja kiertyminen akselin ympäri on estetty, mutta poikkileikkaus voi käyristyä vapaasti. Keskeltä $x=10 h$ se on tuettu siten, että sen siirtyminen akselia vastaan kohtisuorassa tasossa on estetty, mutta se voi kiertyä akselin ympäri vapaasti. Oikeasta päästään $x=20 \mathrm{~h}$ palkki on tuettu siten, että sen siirtyminen, kiertyminen ja poikkileikkauksen käyristyminen on estetty. Koska pistekuorma $F$ ja viivakuorma $q_{0}$ sijaitsevat etäisyydellä $e_{\mathrm{T}}$ vääntökeskiöstä T (kuva 1b), kohdistuu niistä palkkiin myös vääntävä pistemomenttikuorma $-F \cdot e_{\mathrm{T}}$ ja vääntävä tasan jakautunut momenttikuorma $m_{x 0}=-q_{0} e_{\mathrm{T}}$.

Poikkileikkausanalyysi suoritettiin tässä elementtimenetelmällä käyttäen lineaarisia kolmioelementtejä. Liitteessä F on esitetty poikkileikkauksen käyristymisfunktioiden jakaumat. Sen tuloksena saatiin poikkileikkauksen taivutukseen liittyville jäykkyyksille $E A \approx 2,777 E h^{2}, E I_{y} \approx 0,8375 E h^{4}, E I_{z} \approx 0,2993 E h^{4}, E I_{y z} \approx 0,0543 E h^{4}, G A \approx 1,126 E h^{2}$ ja leikkauskorjauskertoimille $k_{y}=0,5447, k_{z} \approx 0,3235, k_{y z} \approx 0,0053$. Edelleen saatiin vääntöön liittyville jäykkyyksille $G J \approx 0,07793 E h^{4}, E I_{\phi} \approx 0,1352 E h^{5}$ ja vääntökeskiön asemalle $e_{\mathrm{T}}=0,3278 \mathrm{~h}$.

Koska rakenteeseen ei kohdistu akselin suuntaista kuormitusta, veto/puristustehtävä antaa nollatuloksen. Taivutustehtävän ratkaisuna on kuvissa 2-5 esitetty taipumien $v(x)$ ja $w(x)$, poikkileikkauksen kiertymien $\theta_{z}(x)$ ja $\theta_{y}(x)$, taivutusmomenttien $M_{z}(x)$ ja $M_{y}(x)$ sekä leikkausvoimien $Q_{y}(x)$ ja $Q_{z}(x)$ jakaumat. Havaitaan, että vaikka kuormitus on pystysuora, palkki taipuu myös vaakasuunnassa sekä taivutusmomentti $M_{y}$ ja leikkausvoima $Q_{z}$ ovat nollasta eroavia. Vääntötehtävän ratkaisuna on kuvissa 6-8 esitetty poikkileikkauksen kiertymän $\theta_{x}(x)$, sen derivaatan $\theta_{x}^{\prime}(x)$, kokonaisvääntö-momentin $M_{x}(x)$, Saint-Venantin vääntömomentin $T(x)$, käyristymismomentin $B(x)$ ja sen derivaatan $B^{\prime}(x)$ jakaumat.

Lopuksi määritettiin jännitysjakaumat poikkileikkauksessa $x=2,5 h$ (kuva 1a). Taivutuksen jännitysresultanteille tässä poikkileikkauksessa saatiin $M_{z} \approx 0,8663 F h$, $M_{y} \approx 0,0008102 F h, Q_{y} \approx 0,3465 F$ ja $Q_{z} \approx 0,00034 F$ (kuvat 4 ja 5) sekä väännön jännitysresultanteille saatiin $T \approx-0,3234 F h, B \approx-0,03181 F h^{2}$ ja $B^{\prime} \approx-0,02526 F h$ (kuvat 7 ja 8). Kuvissa 9 ja 10 on esitetty sekä (a) taivutuksesta että (b) väännöstä aiheutuvat normaalijännityksen $\sigma_{x}$ ja leikkausjännityksen itseisarvon $\tau=\sqrt{\tau_{x y}^{2}+\tau_{x z}^{2}}$ jakaumat tarkasteltavassa poikkileikkauksessa. 

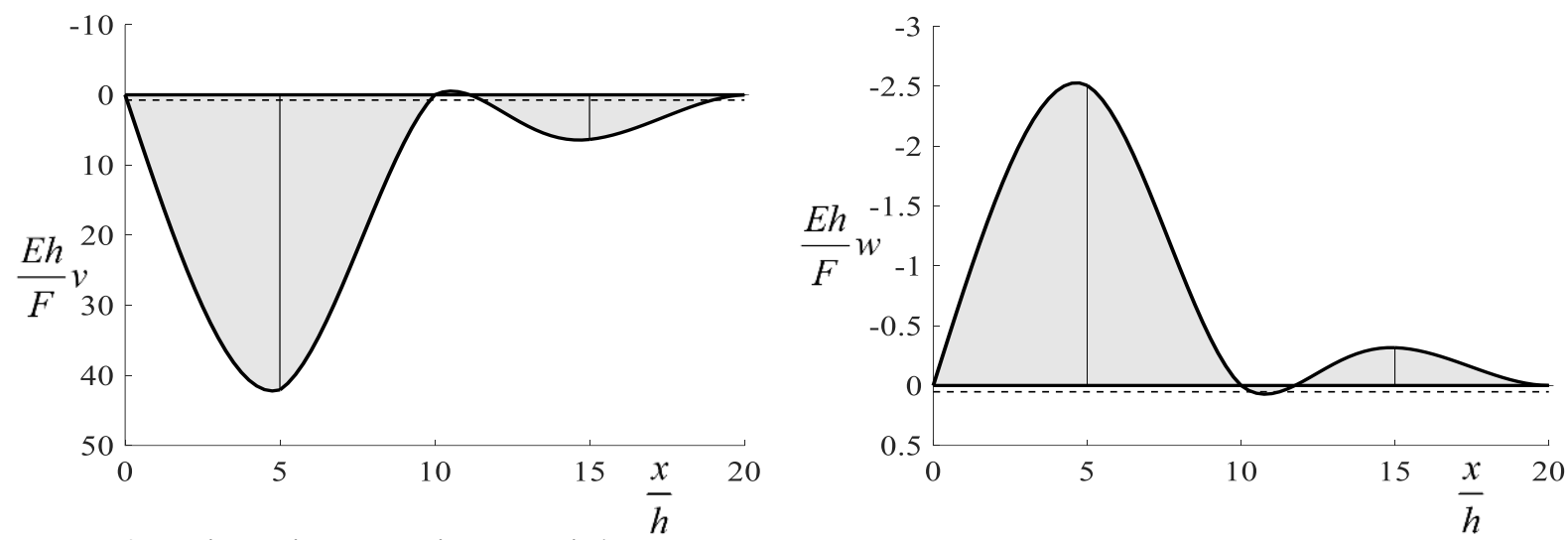

Kuva 2. Taipumien $v(x)$ ja $w(x)$ jakaumat
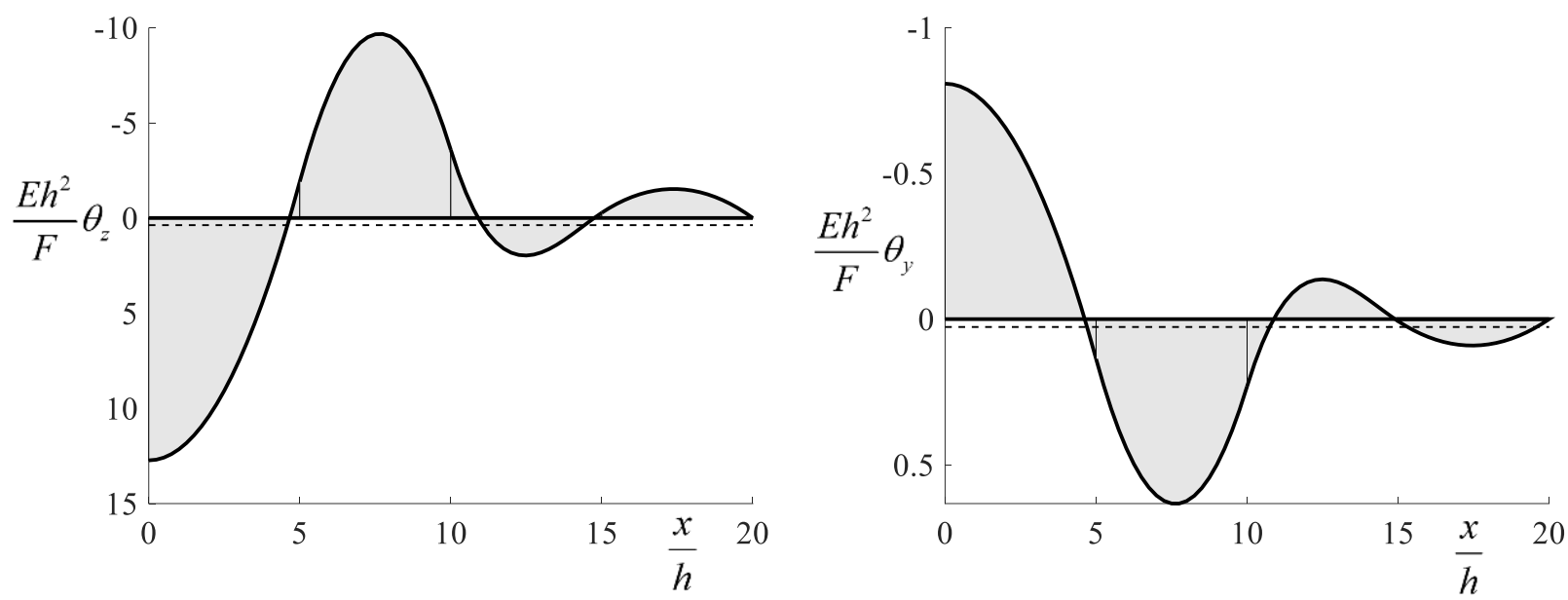

Kuva 3. Poikkileikkauksen kiertymien $\theta_{z}(x)$ ja $\theta_{y}(x)$ jakaumat
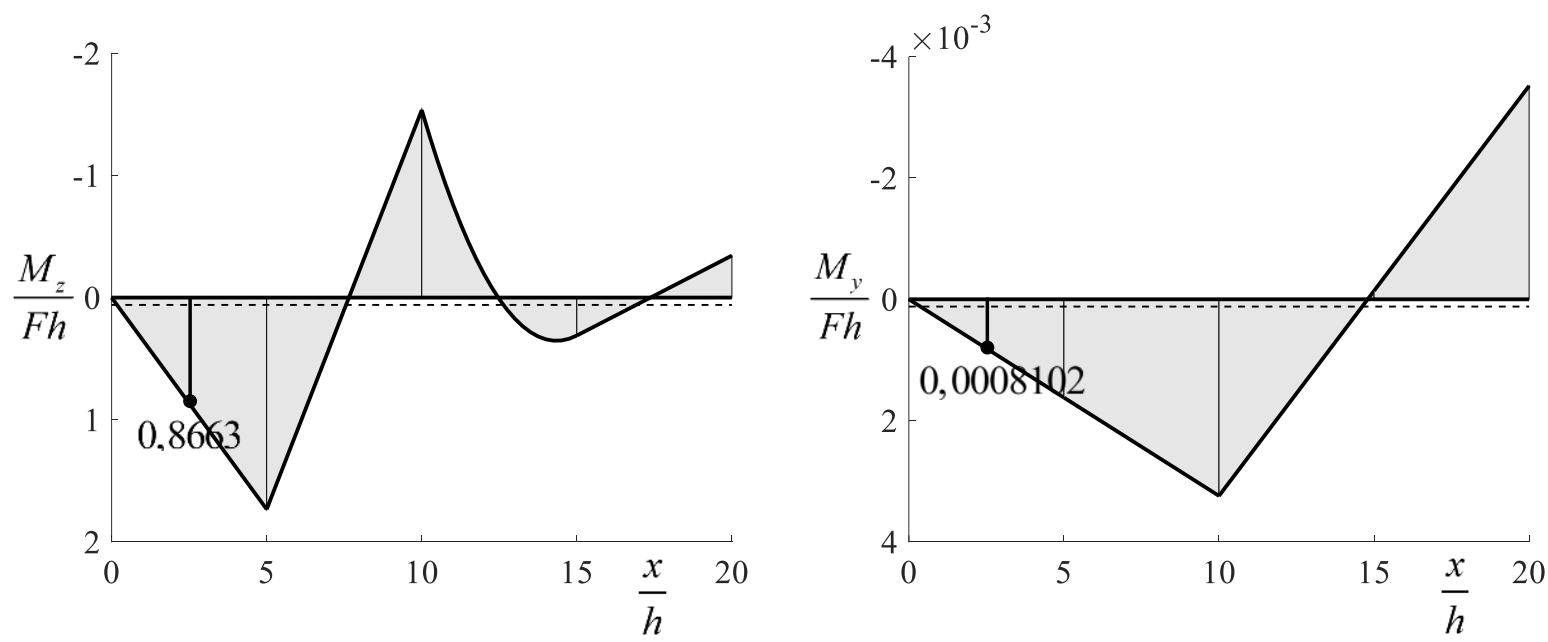

Kuva 4. Tavutusmomenttien $M_{z}(x)$ ja $M_{y}(x)$ jakaumat sekä niiden arvot tarkasteltavassa poikkileikkauksessa $x=2,5 \mathrm{~h}$ 

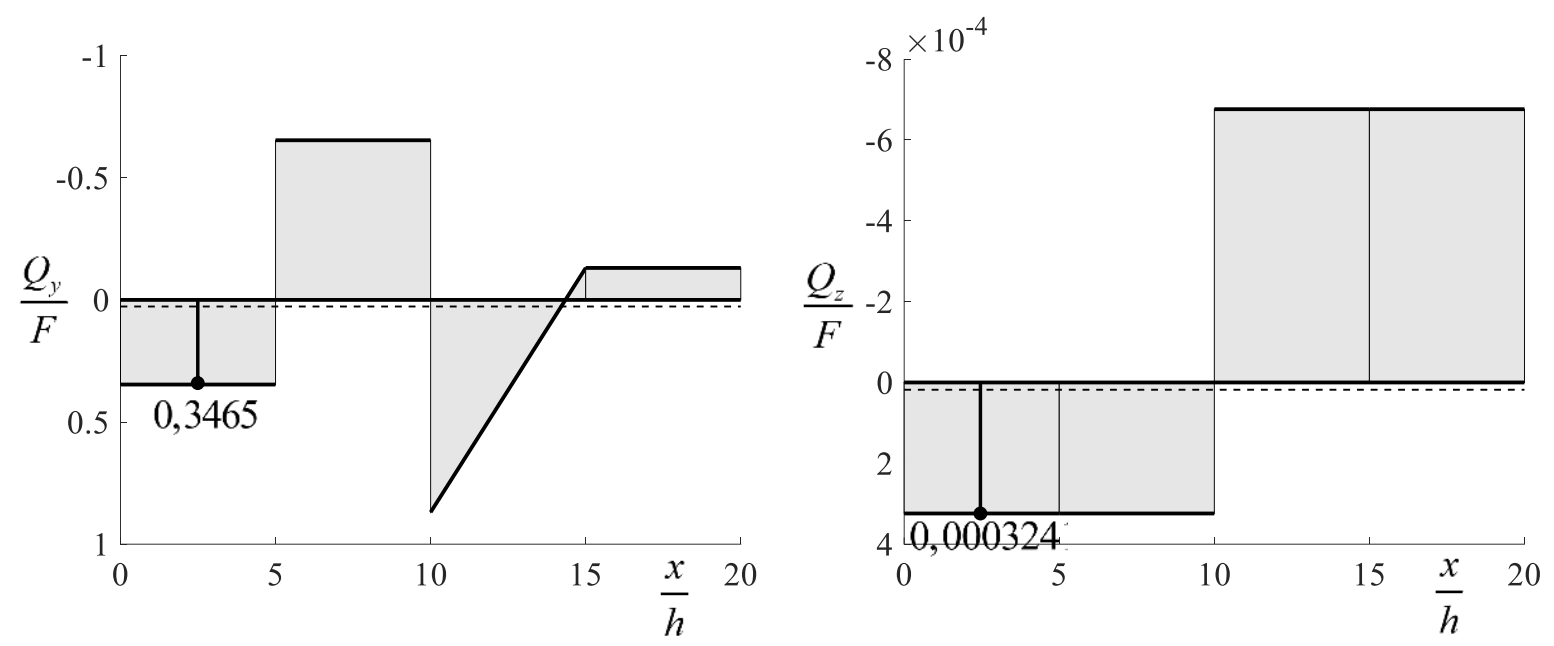

Kuva 5. Leikkausvoimien $Q_{y}(x)$ ja $Q_{z}(x)$ jakaumat sekä niiden arvot tarkasteltavassa poikkileikkauksessa $x=2,5 h$

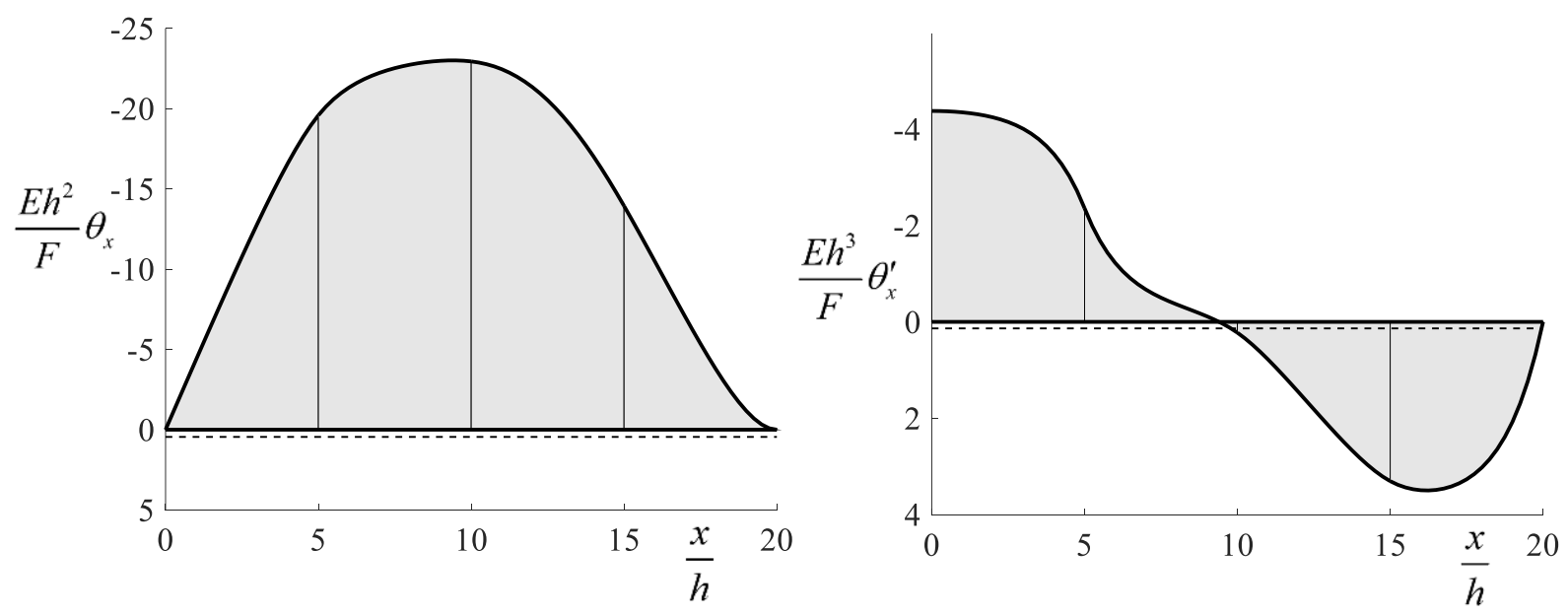

Kuva 6. Poikkileikkauksen kiertymän $\theta_{x}(x)$ ja sen derivaatan $\theta_{x}^{\prime}(x)$ (vääntymän) jakaumat 

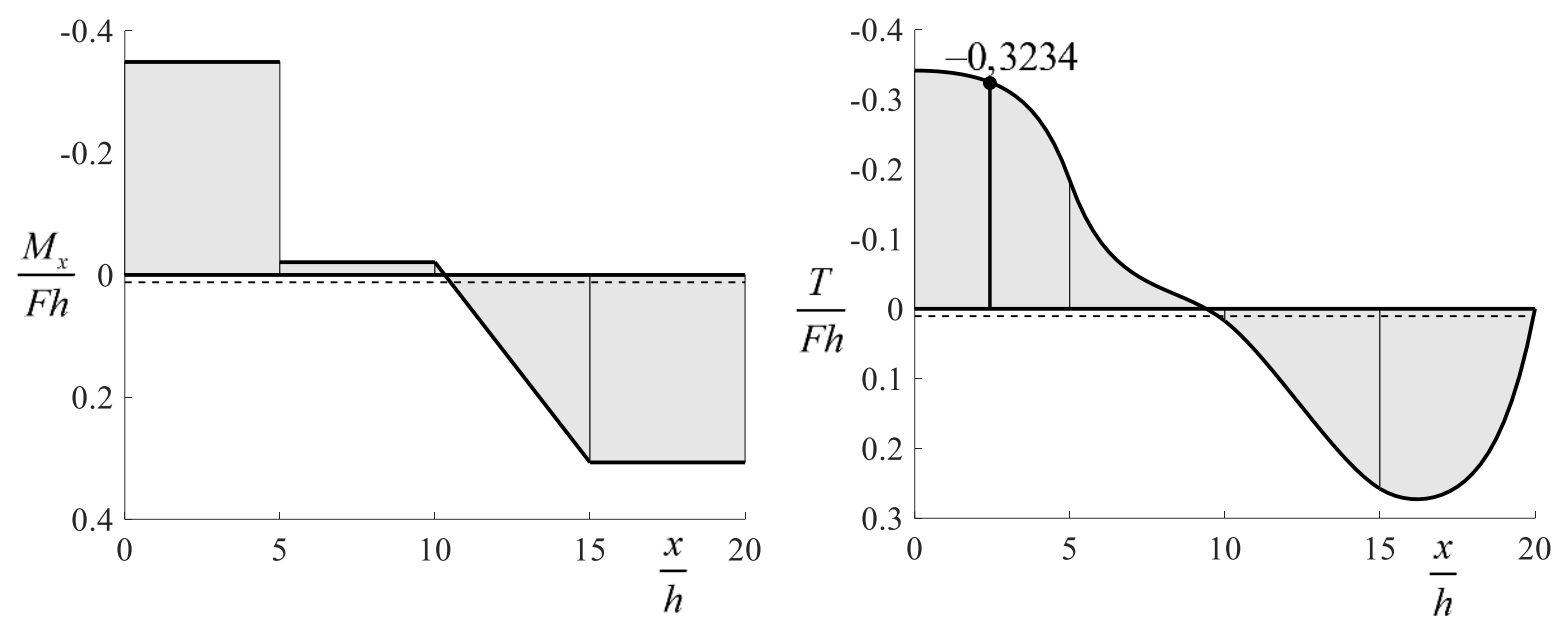

Kuva 7. Kokonaisvääntömomentin $M_{x}(x)$ ja Saint-Venantin vääntömomentin $T(x)$ jakaumat sekä jälkimmäisen arvo tarkasteltavassa poikkileikkauksessa $x=2,5 \mathrm{~h}$
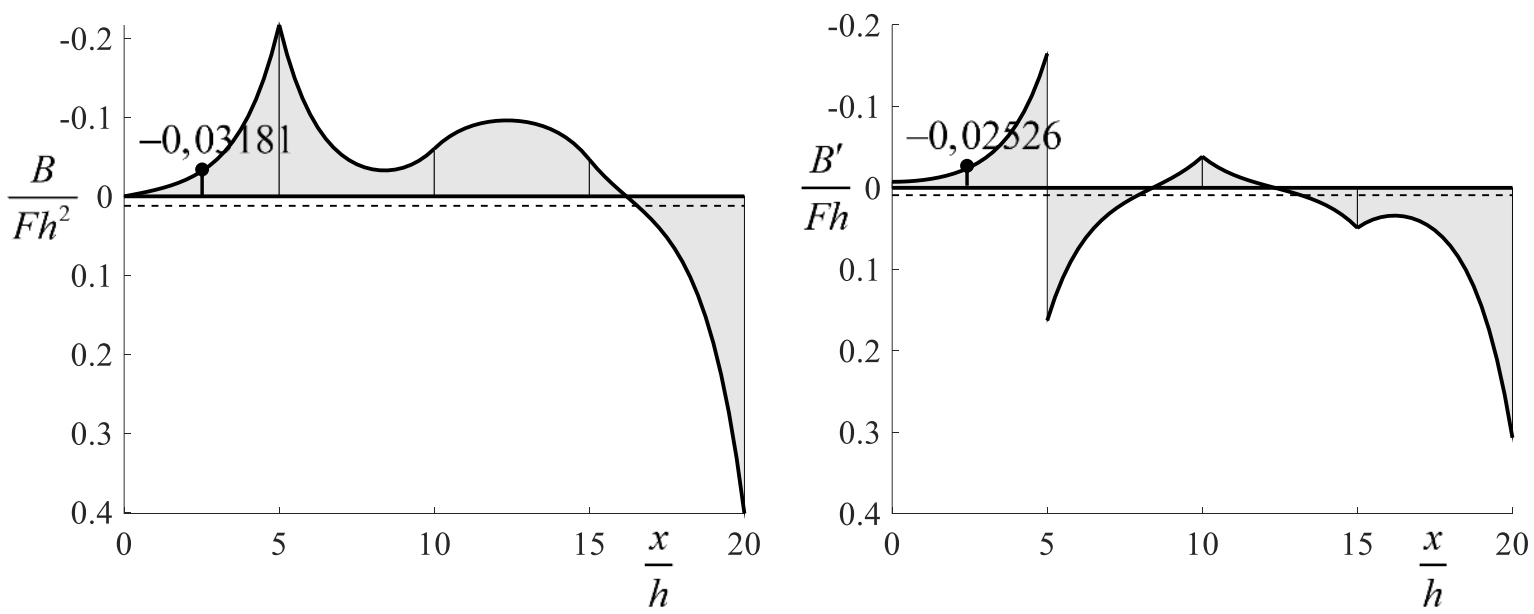

Kuva 8. Käyristymismomentin $B(x)$ ja sen derivaatan $B^{\prime}(x)$ jakaumat sekä niiden arvot tarkasteltavassa poikkileikkauksessa $x=2,5 h$

\section{Johtopäätökset}

Artikkelin ensimmäisessä osassa esitettiin teoria, jonka avulla voidaan määrittää taivutetun ja väännetyn suoran palkin siirtymä- ja jännitystila systemaattisesti ja perinteisiä teorioita tarkemmin. Palkin poikkileikkaus voi olla muodoltaan mielivaltainen ja koostua myös useammasta materiaalista. Tässä artikkelin toisessa osassa teoriaa sovellettiin käyttäen elementtimenetelmää. Ensimmäiseksi johdettiin elementtiyhtälöt poikkileikkaukseen liittyvien käyristymisfunktioiden määrittämiseksi. Yksityiskohtaiset lausekkeet elementtimatriisille ja elementtivektoreille esitettiin lineaarisen kolmioelementin tapauksessa. Toiseksi esitettiin, kuinka palkkitehtävän poikkileikkaussuureet voidaan määrittää, kun käyristymisfunktioiden elementtiapproksimaatiot tunnetaan. Kolmanneksi esitettiin palkkitehtävän analyyttinen ratkaisu. Samalla tavalla kuin perinteisissä palkkiteorioissa veto/puristus-, taivutus- ja vääntötehtävät voitiin käsitellä erikseen ja kullakin on olemassa analyyttinen ratkaisu. Näihin analyyttisiin ratkaisuihin perustuen johdettiin elementit, 
joiden avulla saadaan palkkitehtävän tarkka ratkaisu monimutkaisemmissa kuormitus- ja tuentatapauksissa. Neljänneksi esitettiin, kuinka palkin tietyn poikkileikkauksen jännitysjakaumat voidaan määrittää, kun jännitysresultantit ja käyristymisfunktioiden elementtiapproksimaatiot tunnetaan. Artikkelin lopussa menetelmän eri vaiheita demonstroitiin laskentaesimerkin avulla.
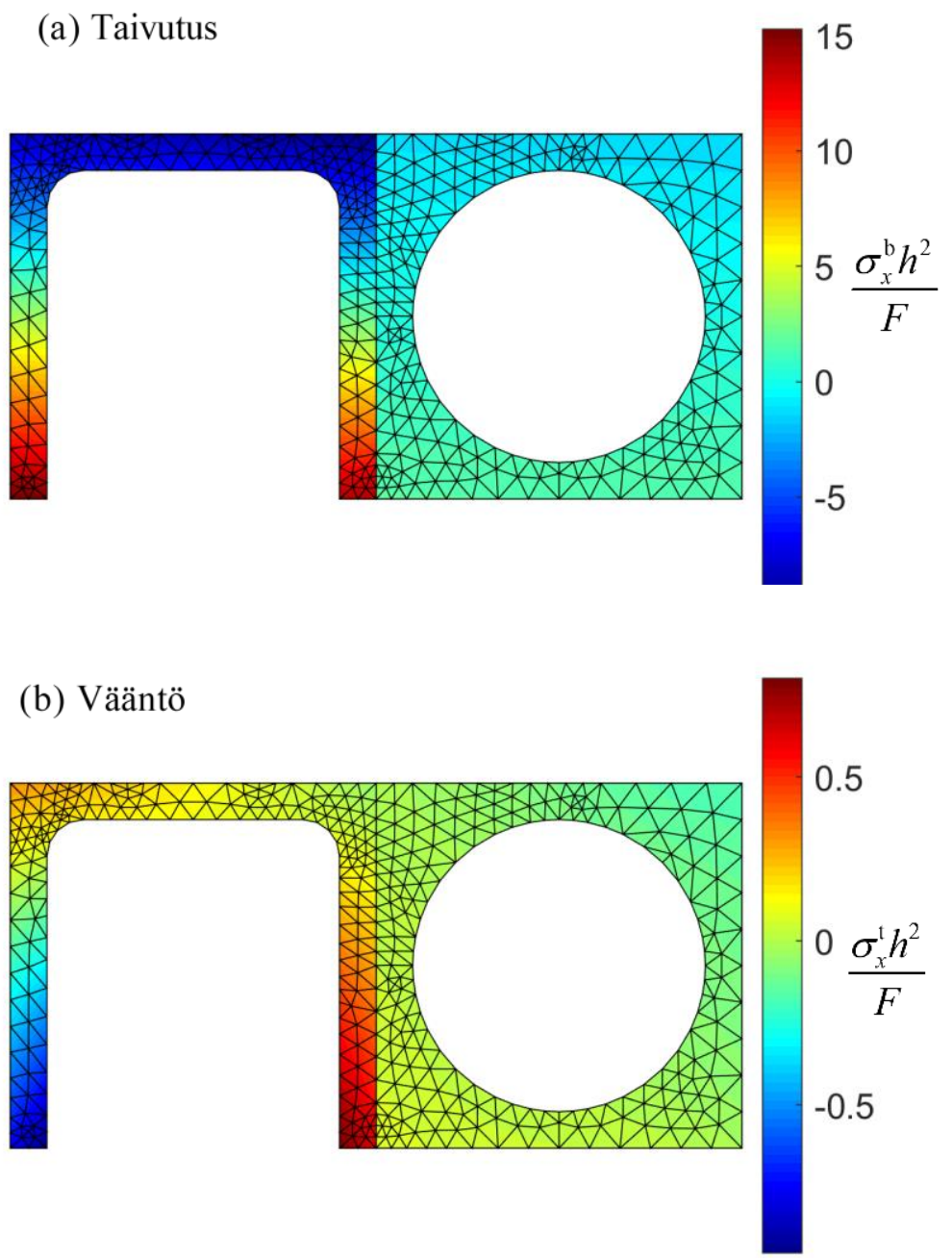

Kuva 9. (a) Taivutuksesta ja (b) väännöstä syntyvä normaalijännitys 


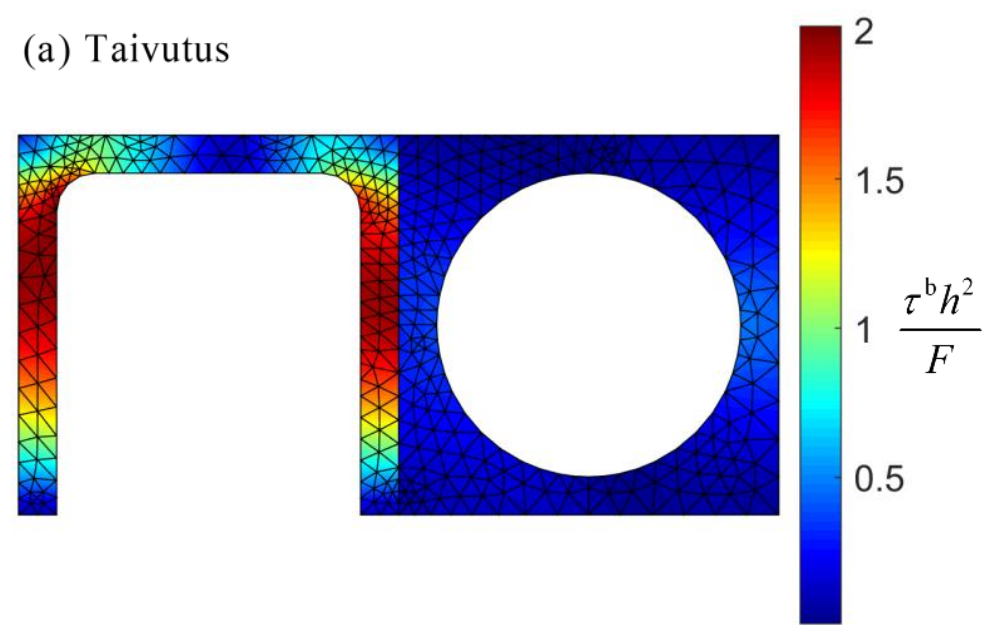

(b) Vääntö

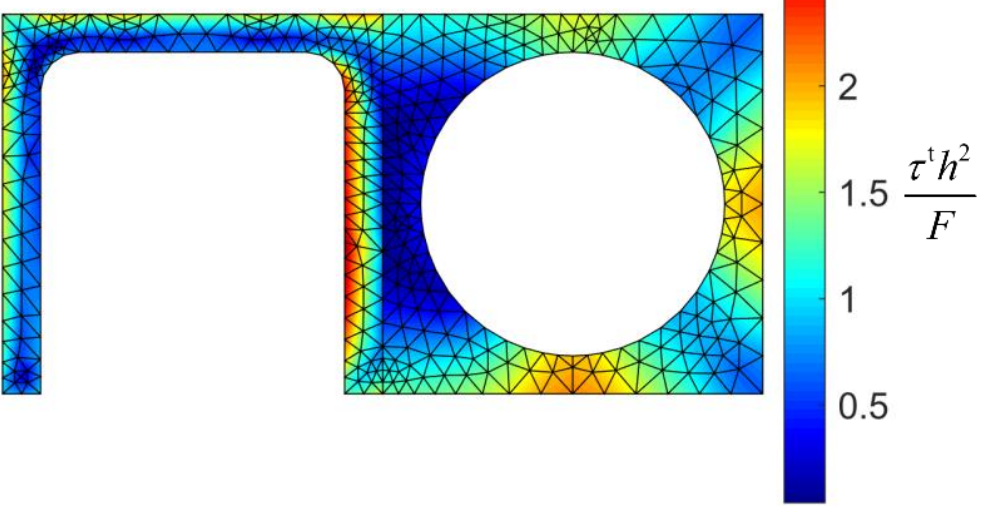

Kuva 10. (a) Taivutuksesta ja (b) väännöstä syntyvä kokonaisleikkausjännitys

\section{Viiteet}

[1] J. Aalto, Taivutuksesta ja väännöstä, osa I: Teoria, Rakenteiden Mekaniikka (Journal of Structural Mechanics), Vol. 50, Nro 4, 2017, s. 376-404. https://doi.org/10.23998/rm.64856

[2] J.S. Przemieniecki, Theory of matrix structural analysis, McGraw-Hill, New York, 1968.

[3] C.F. Kollbrunner and K. Basler, Torsion in Structures, Springer-Verlag, 1969.

Jukka Aalto

Aalto-yliopisto, Insinööritieteiden korkeakoulu, Rakennustekniikan laitos PL 12100, 00076 Aalto

jukka.aalto@aalto.fi 


\section{Liitteet}

\section{A Elementtimatriisi ja elementtivektorit lineaarisen kolmioelementin tapauksessa}

Tässä tarkastelussa poikkileikkauksen kimmomoduuli $E$ ja liukumoduuli $G$ otaksutaan elementin alueella vakioksi. Käytetään hyväksi seuraavia lineaarisen kolmioelementin muotofunktioille $N_{i}^{e}(y, z)$ päteviä tuloksia

$$
\begin{gathered}
\frac{\partial N_{i}^{e}}{\partial y}=\frac{b_{i}}{2 A^{e}}, \quad \frac{\partial N_{i}^{e}}{\partial z}=\frac{c_{i}}{2 A^{e}}, \quad i=1,2,3, \\
\int_{A^{e}} N_{i}^{e} \mathrm{~d} A=\frac{A^{e}}{3}, \quad \int_{A^{e}} \frac{\partial N_{i}^{e}}{\partial y} \mathrm{~d} A=\frac{b_{i}}{2}, \quad \int_{A^{e}} \frac{\partial N_{i}^{e}}{\partial z} \mathrm{~d} A=\frac{c_{i}}{2}, \quad i=1,2,3
\end{gathered}
$$

ja

$$
\left.\begin{array}{l}
\int_{A^{e}} N_{i}^{e} N_{j}^{e} \mathrm{~d} A=\frac{A^{e}}{6}, \quad \operatorname{kun} i=j, \quad \int_{A^{e}} N_{i}^{e} N_{j}^{e} \mathrm{~d} A=\frac{A^{e}}{12}, \operatorname{kun} i \neq j \\
\int_{A^{e}} \frac{\partial N_{i}^{e}}{\partial y} N_{j}^{e} \mathrm{~d} A=\frac{b_{i}}{6}, \quad \int_{A^{e}} \frac{\partial N_{i}^{e}}{\partial z} N_{j}^{e} \mathrm{~d} A=\frac{c_{i}}{6}
\end{array}\right\} i, j=1,2,3 .
$$

Näissä kaavoissa $A^{e}$ on elementin pinta-ala ja

$$
\begin{aligned}
& b_{1}=z_{2}^{e}-z_{3}^{e}, \quad b_{2}=z_{3}^{e}-z_{1}^{e}, \quad b_{3}=z_{1}^{e}-z_{2}^{e}, \\
& c_{1}=y_{3}^{e}-y_{2}^{e}, \quad c_{2}=y_{1}^{e}-y_{3}^{e}, \quad c_{3}=y_{2}^{e}-y_{1}^{e} .
\end{aligned}
$$

Systeemimatriisin $\mathbf{K}$ alkioita (6) vastavan elementtimatriisin $\mathbf{K}^{e}$ alkioille saadaan

$$
K_{i j}^{e}=G^{e} \int_{A^{e}}\left(\frac{\partial N_{i}^{e}}{\partial y} \frac{\partial N_{j}^{e}}{\partial y}+\frac{\partial N_{i}^{e}}{\partial z} \frac{\partial N_{j}^{e}}{\partial z}\right) \mathrm{d} A=\frac{G^{e}}{4 A^{e}}\left(b_{i} b_{j}+c_{i} c_{j}\right), \quad i, j=1,2,3 .
$$

Systeemivektorin $\mathbf{R}_{\Phi}$ alkioita (7a) vastavan elementtivektorin $\mathbf{R}_{\Phi}^{e}$ alkioille saadaan

$$
R_{\Phi i}^{e}=G^{e} \int_{A}\left(\frac{\partial N_{i}^{e}}{\partial y} z-\frac{\partial N_{i}^{e}}{\partial z} y\right) \mathrm{d} A=\frac{G^{e}}{2 A^{e}}\left(b_{i} \int_{A} z \mathrm{~d} A-c_{i} \int_{A} y \mathrm{~d} A\right) .
$$

Sijoittamalla näihin koordinaattien esitykset

$$
y=N_{1}^{e} y_{1}^{e}+N_{2}^{e} y_{2}^{e}+N_{3}^{e} y_{3}^{e}, \quad z=N_{1}^{e} z_{1}^{e}+N_{2}^{e} z_{2}^{e}+N_{3}^{e} z_{3}^{e}
$$

saadaan tulos

$$
\begin{aligned}
R_{\Phi i}^{e}= & \frac{G^{e}}{2 A^{e}}\left[b_{i}\left(\int_{A^{e}} N_{1}^{e} \mathrm{~d} A z_{1}^{e}+\int_{A^{e}} N_{2}^{e} \mathrm{~d} A z_{2}^{e}+\int_{A^{e}} N_{3}^{e} \mathrm{~d} A z_{3}^{e}\right)\right. \\
& \left.\quad-c_{i}\left(\int_{A^{e}} N_{1}^{e} \mathrm{~d} A y_{1}^{e}+\int_{A^{e}} N_{2}^{e} \mathrm{~d} A y_{2}^{e}+\int_{A^{e}} N_{3}^{e} \mathrm{~d} A y_{3}^{e}\right)\right] \\
= & \frac{G^{e}}{2}\left(b_{i} \bar{z}^{e}-c_{i} \bar{y}^{e}\right) .
\end{aligned}
$$

Systeemivektorin $\mathbf{R}_{x}$ alkioita (7b) vastavan elementtivektorin $\mathbf{R}_{x}^{e}$ alkioille saadaan

$$
R_{x i}^{e}=E^{e} \int_{A^{e}} N_{i}^{e} \phi \mathrm{d} A .
$$


Sijoittamalla tähän $\phi$ :n elementtiapproksimaatio

$$
\phi=N_{1}^{e} \phi_{1}^{e}+N_{2}^{e} \phi_{2}^{e}+N_{3}^{e} \phi_{3}^{e}
$$

saadaan edelleen

$$
R_{x i}^{e}=E^{e}\left(\int_{A^{e}} N_{i}^{e} N_{1}^{e} \mathrm{~d} A \phi_{1}^{e}+\int_{A^{e}} N_{i}^{e} N_{2}^{e} \mathrm{~d} A \phi_{2}^{e}+\int_{A^{e}} N_{i}^{e} N_{3}^{e} \mathrm{~d} A \phi_{3}^{e}\right) .
$$

Koko elementtivektorille $\mathbf{R}_{x}^{e}$ saadaan tulos

$$
\mathbf{R}_{x}^{e} \equiv\left\{\begin{array}{l}
R_{x 1}^{e} \\
R_{x 2}^{e} \\
R_{x 3}^{e}
\end{array}\right\}=\frac{E^{e} A^{e}}{12}\left\{\begin{array}{l}
2 \phi_{1}^{e}+\phi_{2}^{e}+\phi_{3}^{e} \\
\phi_{1}^{e}+2 \phi_{2}^{e}+\phi_{3}^{e} \\
\phi_{1}^{e}+\phi_{2}^{e}+2 \phi_{3}^{e}
\end{array}\right\} .
$$

Systeemivektorin $\mathbf{R}_{y}$ alkioita (7c) vastavan elementtivektorin $\mathbf{R}_{y}^{e}$ alkioille saadaan

$$
R_{y i}^{e}=E^{e} \int_{A^{e}} N_{i}^{e} y \mathrm{~d} A .
$$

Sijoittamalla tähän koordinaatin $y$ elementtiapproksimaatio (A.4) saadaan edelleen

$$
R_{y i}^{e}=E^{e}\left(\int_{A^{e}} N_{i}^{e} N_{1}^{e} \mathrm{~d} A y_{1}^{e}+\int_{A^{e}} N_{i}^{e} N_{2}^{e} \mathrm{~d} A y_{2}^{e}+E \int_{A^{e}} N_{i}^{e} N_{3}^{e} \mathrm{~d} A y_{3}^{e}\right) .
$$

Koko elementtivektorille $\mathbf{R}_{y}^{e}$ saadaan tulos

$$
\mathbf{R}_{y}^{e} \equiv\left\{\begin{array}{l}
R_{y 1}^{e} \\
R_{y 2}^{e} \\
R_{y 3}^{e}
\end{array}\right\}=\frac{E^{e} A^{e}}{12}\left\{\begin{array}{l}
2 y_{1}^{e}+y_{2}^{e}+y_{3}^{e} \\
y_{1}^{e}+2 y_{2}^{e}+y_{3}^{e} \\
y_{1}^{e}+y_{2}^{e}+2 y_{3}^{e}
\end{array}\right\} .
$$

Elementtivektorille $\mathbf{R}_{z}^{e}$ saadaan vastaavasti tulos

$$
\mathbf{R}_{z}^{e}=\frac{E^{e} A^{e}}{12}\left\{\begin{array}{c}
2 z_{1}^{e}+z_{2}^{e}+z_{3}^{e} \\
z_{1}^{e}+2 z_{2}^{e}+z_{3}^{e} \\
z_{1}^{e}+z_{2}^{e}+2 z_{3}^{e}
\end{array}\right\} .
$$




\section{B Poikkileikkaussuureiden elementtiosuudet lineaarisen kolmioelementin tapauksessa}

Kimmomoduulilla painotetun pinta-alan momentin $E A$ elementtiosuudelle saadaan

$$
(E A)^{e}=E^{e} \int_{A^{e}} \mathrm{~d} A=E^{e} A^{e} .
$$

Kimmomoduulilla painotetun staattisen momentin $E S_{z}$ elementtiosuudelle saadaan

$$
\begin{aligned}
\left(E S_{z}\right)^{e} & =E^{e} \int_{A^{e}} y \mathrm{~d} A=E^{e}\left(\int_{A^{e}} N_{1}^{e} \mathrm{~d} A y_{1}^{e}+\int_{A^{e}} N_{2}^{e} \mathrm{~d} A y_{2}^{e}+\int_{A^{e}} N_{3}^{e} \mathrm{~d} A y_{3}^{e}\right)=E^{e} A^{e} \frac{y_{1}^{e}+y_{2}^{e}+y_{3}^{e}}{3} \\
& =E^{e} A^{e} \bar{y}^{e},
\end{aligned}
$$

ja staattisen momentin $E S_{y}$ elementtiosuudelle vastaavasti

$$
\left(E S_{y}\right)^{e}=E^{e} \int_{A^{e}} z \mathrm{~d} A=E^{e} A^{e} \bar{z}^{e} .
$$

Kimmomoduulilla painotetun tulomomentin $E I_{y z}$ elementtiosuudelle saadaan

$$
\begin{aligned}
& \left(E I_{y z}\right)^{e}=E^{e} \int_{A^{e}} y z \mathrm{~d} A=E^{e} \int_{A^{e}}\left(N_{1}^{e} y_{1}^{e}+N_{2}^{e} y_{2}^{e}+N_{3}^{e} y_{3}^{e}\right)\left(N_{1}^{e} z_{1}^{e}+N_{2}^{e} z_{2}^{e}+N_{3}^{e} z_{3}^{e}\right) \mathrm{d} A \\
& =E^{e}\left[\int_{A^{e}} N_{1}^{e} N_{1}^{e} \mathrm{~d} A y_{1}^{e} z_{1}^{e}+E \int_{A^{e}} N_{2}^{e} N_{2}^{e} \mathrm{~d} A y_{2}^{e} z_{2}^{e}+E \int_{A^{e}} N_{3}^{e} N_{3}^{e} \mathrm{~d} A y_{3}^{e} z_{3}^{e}\right. \\
& \left.\quad+\int_{A^{e}} N_{2}^{e} N_{3}^{e} \mathrm{~d} A\left(y_{2}^{e} z_{3}^{e}+y_{3}^{e} z_{2}^{e}\right)+\int_{A^{e}} N_{2}^{e} N_{3}^{e} \mathrm{~d} A\left(y_{3}^{e} z_{1}^{e}+y_{1}^{e} y_{3}^{e}\right)+\int_{A^{e}} N_{1}^{e} N_{2}^{e} \mathrm{~d} A\left(y_{1}^{e} z_{2}^{e}+y_{2}^{e} z_{1}^{e}\right)\right] \\
& =\frac{E^{e} A^{e}}{12}\left(2 y_{1}^{e} z_{1}^{e}+2 y_{2}^{e} z_{2}^{e}+2 y_{3}^{e} z_{3}^{e}+y_{2}^{e} z_{3}^{e}+y_{3}^{e} z_{2}^{e}+y_{3}^{e} z_{1}^{e}+y_{1}^{e} z_{3}^{e}+y_{1}^{e} z_{2}^{e}+y_{2}^{e} z_{1}^{e}\right) .
\end{aligned}
$$

Taivutusjäykkyyksien $E I_{z}$ ja $E I_{y}$ elementtiosuuksille saadaan vastaavaan tapaan tulokset

$$
\left(E I_{z}\right)^{e}=E^{e} \int_{A^{e}} y^{2} \mathrm{~d} A=\frac{E^{e} A^{e}}{6}\left(y_{1}^{e} y_{1}^{e}+y_{2}^{e} y_{2}^{e}+y_{3}^{e} y_{3}^{e}+y_{2}^{e} y_{3}^{e}+y_{3}^{e} y_{1}^{e}+y_{1}^{e} y_{2}^{e}\right)
$$

ja

$$
\left(E I_{y}\right)^{e}=E^{e} \int_{A^{e}} z^{2} \mathrm{~d} A=\frac{E^{e} A^{e}}{6}\left(z_{1}^{e} z_{1}^{e}+z_{2}^{e} z_{2}^{e}+z_{3}^{e} z_{3}^{e}+z_{2}^{e} z_{3}^{e}+z_{3}^{e} z_{1}^{e}+z_{1}^{e} z_{2}^{e}\right) .
$$

Suureen $E S_{\Phi}$ elementtiosuudelle saadaan

$$
\begin{aligned}
\left(E S_{\Phi}\right)^{e} & =E^{e} \int_{A^{e}} \Phi \mathrm{d} A=E^{e}\left(\int_{A^{e}} N_{1}^{e} \mathrm{~d} A \Phi_{1}^{e}+\int_{A^{e}} N_{2}^{e} \mathrm{~d} A \Phi_{2}^{e}+\int_{A^{e}} N_{3}^{e} \mathrm{~d} A \Phi_{3}^{e}\right) \\
& =E^{e} A^{e} \frac{\Phi_{1}^{e}+\Phi_{2}^{e}+\Phi_{3}^{e}}{3}=E^{e} A^{e} \bar{\Phi}^{e} .
\end{aligned}
$$

Suureen $E I_{y \Phi}$ elementtiosuudelle saadaan 


$$
\begin{aligned}
& \left(E I_{y \Phi}\right)^{e}=E^{e} \int_{A^{e}} z \Phi \mathrm{d} A=E^{e} \int_{A^{e}}\left(N_{1}^{e} z_{1}^{e}+N_{2}^{e} z_{2}^{e}+N_{3}^{e} z_{3}^{e}\right)\left(N_{1}^{e} \Phi_{1}^{e}+N_{2}^{e} \Phi_{2}^{e}+N_{3}^{e} \Phi_{3}^{e}\right) \mathrm{d} A \\
& =E^{e}\left(\int_{A^{e}} N_{1}^{e} N_{1}^{e} \mathrm{~d} A z_{1}^{e} \Phi_{1}^{e}+\int_{A^{e}} N_{2}^{e} N_{2}^{e} \mathrm{~d} A z_{2}^{e} \Phi_{2}^{e}+\int_{A^{e}} N_{3}^{e} N_{3}^{e} \mathrm{~d} A z_{3}^{e} \Phi_{3}^{e}\right. \\
& +\int_{A^{e}} N_{2}^{e} N_{3}^{e} \mathrm{~d} A\left(z_{2}^{e} \Phi_{3}^{e}+z_{3}^{e} \Phi_{2}^{e}\right)+\int_{A^{e}} N_{3}^{e} N_{1}^{e} \mathrm{~d} A\left(z_{3}^{e} \Phi_{1}^{e}+z_{1}^{e} \Phi_{3}^{e}\right)+\int_{A^{e}} N_{1}^{e} N_{2}^{e} \mathrm{~d} A\left(z_{1}^{e} \Phi_{2}^{e}+z_{2}^{e} \Phi_{1}^{e}\right) \\
& =\frac{E^{e} A^{e}}{12}\left(2 z_{1}^{e} \Phi_{1}^{e}+2 z_{2}^{e} \Phi_{2}^{e}+2 z_{3}^{e} \Phi_{3}^{e}+z_{2}^{e} \Phi_{3}^{e}+z_{3}^{e} \Phi_{2}^{e}+z_{3}^{e} \Phi_{1}^{e}+z_{1}^{e} \Phi_{3}^{e}+z_{1}^{e} \Phi_{2}^{e}+z_{2}^{e} \Phi_{1}^{e}\right)
\end{aligned}
$$

Suureen $E I_{z \Phi}$ elementtiosuudelle saadaan vastaavasti

$$
\begin{aligned}
& \left(E I_{z \Phi}\right)^{e}=E^{e} \int_{A^{e}} y \Phi \mathrm{d} A \\
& \quad=\frac{E^{e} A^{e}}{12}\left(2 y_{1}^{e} \Phi_{1}^{e}+2 y_{2}^{e} \Phi_{2}^{e}+2 y_{3}^{e} \Phi_{3}^{e}+y_{2}^{e} \Phi_{3}^{e}+y_{3}^{e} \Phi_{2}^{e}+y_{3}^{e} \Phi_{1}^{e}+y_{1}^{e} \Phi_{3}^{e}+y_{1}^{e} \Phi_{2}^{e}+y_{2}^{e} \Phi_{1}^{e}\right) .
\end{aligned}
$$

Käyristymisjäykkyyden $E I_{\phi}$ elementtiosuudelle saadaan

$$
\left(E I_{\phi}\right)^{e}=E^{e} \int_{A^{e}} \phi^{2} \mathrm{~d} A=\frac{E^{e} A^{e}}{6}\left(\phi_{1}^{e} \phi_{1}^{e}+\phi_{2}^{e} \phi_{2}^{e}+\phi_{3}^{e} \phi_{3}^{e}+\phi_{2}^{e} \phi_{3}^{e}+\phi_{3}^{e} \phi_{1}^{e}+\phi_{1}^{e} \phi_{2}^{e}\right) \text {. }
$$

Leikkausjäykkyyden $G A$ elementtiosuudelle saadaan

$$
(G A)^{e}=G^{e} \int_{A^{e}} \mathrm{~d} A=G^{e} A^{e} .
$$

Vääntöjäykkyyden $G J$ elementtiosuudelle saadaan

$$
\begin{aligned}
(G J)^{e}= & G^{e} \int_{A^{e}}\left[-\left(\frac{\partial \Phi}{\partial y}-z\right) z+\left(\frac{\partial \Phi}{\partial z}+y\right) y\right] \mathrm{d} A \\
= & G^{e}\left[-\left(\frac{b_{1}}{2 A^{e}} \Phi_{1}^{e}+\frac{b_{2}}{2 A^{e}} \Phi_{2}^{e}+\frac{b_{3}}{2 A^{e}} \Phi_{3}^{e}\right) \int_{A^{e}}\left(N_{1}^{e} z_{1}^{e}+N_{2}^{e} z_{2}^{e}+N_{3}^{e} z_{3}^{e}\right) \mathrm{d} A\right. \\
& \left.+\left(\frac{c_{1}}{2 A^{e}} \Phi_{1}^{e}+\frac{c_{2}}{2 A^{e}} \Phi_{2}^{e}+\frac{c_{3}}{2 A^{e}} \Phi_{3}^{e}\right) \int_{A^{e}}\left(N_{1}^{e} y_{1}^{e}+N_{2}^{e} y_{2}^{e}+N_{3}^{e} y_{3}^{e}\right) \mathrm{d} A\right] \\
& +G^{e}\left(\int_{A^{e}} z^{2} \mathrm{~d} A+\int_{A^{e}} y^{2} \mathrm{~d} A\right) \\
= & \frac{G^{e} A^{e}}{6}\left[-3\left(b_{1} \Phi_{1}^{e}+b_{2} \Phi_{2}^{e}+b_{3} \Phi_{3}^{e}\right) \bar{z}^{e}+3\left(c_{1} \Phi_{1}^{e}+c_{2} \Phi_{2}^{e}+c_{3} \Phi_{3}^{e}\right) \bar{y}^{e}\right. \\
& \quad+y_{1}^{e} y_{1}^{e}+y_{2}^{e} y_{2}^{e}+y_{3}^{e} y_{3}^{e}+y_{2}^{e} y_{3}^{e}+y_{3}^{e} y_{1}^{e}+y_{1}^{e} y_{2}^{e} \\
& \left.\quad+z_{1}^{e} z_{1}^{e}+z_{2}^{e} z_{2}^{e}+z_{3}^{e} z_{3}^{e}+z_{2}^{e} z_{3}^{e}+z_{3}^{e} z_{1}^{e}+z_{1}^{e} z_{2}^{e}\right] .
\end{aligned}
$$

Suureiden $E I_{y \Psi_{y}}, E I_{z \Psi_{y}}, E I_{y \Psi_{z}}$ ja $E I_{z \Psi_{z}}$ elementtiosuuksille saadaan vastaavaan tapaan 


$$
\begin{aligned}
\left(E I_{y \Psi_{y}}\right)^{e}= & E^{e} \int_{A^{e}} z \Psi_{y} \mathrm{~d} A \\
= & \frac{E^{e} A^{e}}{12}\left(2 z_{1}^{e} \Psi_{y 1}^{e}+2 z_{2}^{e} \Psi_{y 2}^{e}+2 z_{3}^{e} \Psi_{y 3}^{e}\right. \\
& \left.\quad+z_{2}^{e} \Psi_{y 3}^{e}+z_{3}^{e} \Psi_{y 2}^{e}+z_{3}^{e} \Psi_{y 1}^{e}+z_{1}^{e} \Psi_{y 3}^{e}+z_{1}^{e} \Psi_{y 2}^{e}+z_{2}^{e} \Psi_{y 1}^{e}\right) \\
\left(E I_{z \Psi_{y}}\right)^{e}= & E^{e} \int_{A^{e}} y \Psi_{y} \mathrm{~d} A \\
= & \frac{E^{e} A^{e}}{12}\left(2 y_{1}^{e} \Psi_{y 1}^{e}+2 y_{2}^{e} \Psi_{y 2}^{e}+2 y_{3}^{e} \Psi_{y 3}^{e}\right. \\
& \left.\quad+y_{2}^{e} \Psi_{y 3}^{e}+y_{3}^{e} \Psi_{y 2}^{e}+y_{3}^{e} \Psi_{y 1}^{e}+y_{1}^{e} \Psi_{y 3}^{e}+y_{1}^{e} \Psi_{y 2}^{e}+y_{2}^{e} \Psi_{y 1}^{e}\right), \\
\left(E I_{y \Psi_{z}}\right)^{e}= & E^{e} \int_{A^{e}} z \Psi_{z} \mathrm{~d} A \\
= & \frac{E^{e} A^{e}}{12}\left(2 z_{1}^{e} \Psi_{z 1}^{e}+2 z_{2}^{e} \Psi_{z 2}^{e}+2 z_{3}^{e} \Psi_{z 3}^{e}\right. \\
& \left.\quad+z_{2}^{e} \Psi_{z 3}^{e}+z_{3}^{e} \Psi_{z 2}^{e}+z_{3}^{e} \Psi_{z 1}^{e}+z_{1}^{e} \Psi_{z 3}^{e}+z_{1}^{e} \Psi_{z 2}^{e}+z_{2}^{e} \Psi_{z 1}^{e}\right), \\
\left(E I_{z \Psi_{z}}\right)^{e}= & E^{e} \int_{A^{e}} y \Psi_{z} \mathrm{~d} A \\
= & \frac{E^{e} A^{e}}{12}\left(2 y_{1}^{e} \Psi_{z 1}^{e}+2 y_{2}^{e} \Psi_{z 2}^{e}+2 y_{3}^{e} \Psi_{z 3}^{e}\right. \\
& \left.\quad+y_{2}^{e} \Psi_{z 3}^{e}+y_{3}^{e} \Psi_{z 2}^{e}+y_{3}^{e} \Psi_{z 1}^{e}+y_{1}^{e} \Psi_{z 3}^{e}+y_{1}^{e} \Psi_{z 2}^{e}+y_{2}^{e} \Psi_{z 1}^{e}\right) .
\end{aligned}
$$




\section{$C$ Vedetyn/puristetun palkin elementtiratkaisu}

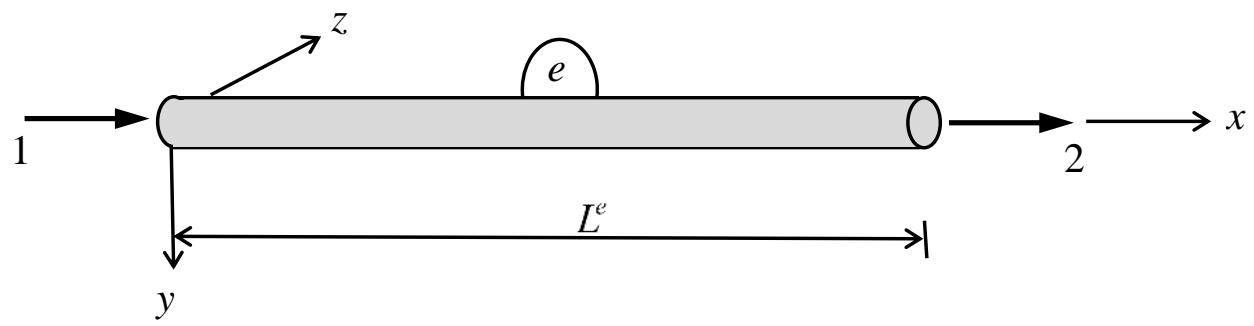

Kuva C.1. Vedetyn/puristetun palkkielementin vapausasteet

\section{C.1 Elementtiyhtälöt}

Aksiaalisen siirtymän differentiaaliyhtälön (32) yleinen ratkaisu (34) voidaan esittāä muodossa

$$
u(x)=\left[\begin{array}{ll}
x & 1
\end{array}\right] \mathbf{C}+u_{0}(x)
$$

missä

$$
\mathbf{C}=\left\{\begin{array}{l}
C_{1} \\
C_{2}
\end{array}\right\} .
$$

Sitä vastaten saadaan normaalivoimalle elementin alueella kaavalla (33)

$$
N(x)=E A[1 \quad 0] \mathbf{C}+N_{0}(x),
$$

missä suuretta

$$
N_{0}(x)=E A u_{0}^{\prime}(x)
$$

kutsutaan tässä yksityisratkaisua $u_{0}(x)$ vastaavaksi normaalivoimaksi. Yhteensopivuusehdot elementin päissä ovat

$$
\left\{\begin{array}{l}
a_{1}^{e} \\
a_{2}^{e}
\end{array}\right\}=\left\{\begin{array}{l}
u(0) \\
u\left(L^{e}\right)
\end{array}\right\}
$$

ja niistä seuraa vapausastesiirtymien ja integrointivakioiden välille yhtälö

$$
\mathbf{a}^{e}=\mathcal{A C}+\boldsymbol{a}_{0},
$$

missä

$$
\mathbf{a}^{e}=\left\{\begin{array}{c}
a_{1}^{e} \\
a_{2}^{e}
\end{array}\right\}, \quad \mathcal{A}=\left[\begin{array}{cc}
0 & 1 \\
L^{e} & 1
\end{array}\right], \quad \boldsymbol{a}_{0}=\left\{\begin{array}{c}
u_{0}(0) \\
u_{0}\left(L^{e}\right)
\end{array}\right\} .
$$

Tasapainoehdot elementin päissä ovat

$$
\left\{\begin{array}{c}
F_{1}^{e} \\
F_{2}^{e}
\end{array}\right\}=\left\{\begin{array}{c}
-N(0) \\
N\left(L^{e}\right)
\end{array}\right\}
$$

ja niistä seuraa vapausastevoimien ja integrointivakioiden välille yhtälö

$$
\mathbf{F}^{e}=\mathcal{B C}+\mathcal{F}_{0}
$$

missä 


$$
\mathbf{F}^{e}=\left\{\begin{array}{c}
F_{1}^{e} \\
F_{2}^{e}
\end{array}\right\}, \quad \mathcal{B}=E A\left[\begin{array}{cc}
-1 & 0 \\
1 & 0
\end{array}\right], \quad \mathcal{F}_{0}=\left\{\begin{array}{c}
-N_{0}(0) \\
N_{0}\left(L^{e}\right)
\end{array}\right\} .
$$

Yhtälöistä (C.6) saadaan integrointivakioille

$$
\mathbf{C}=\mathcal{A}^{-1}\left(\mathbf{a}^{e}-\boldsymbol{a}_{0}\right) .
$$

Yhtälöistä (C.9) ja (C.11) seuraa elementin vapausastevoimien ja -siirtymien välille yhtälö

missä

$$
\mathbf{F}^{e}=\mathbf{K}^{e} \mathbf{a}^{e}-\mathbf{R}^{e}
$$

on elementin jäykkyysmatriisi ja

$$
\mathbf{K}^{e}=\mathcal{B A}^{-1}
$$

$$
\mathbf{R}^{e}=\mathbf{K}^{e} \boldsymbol{a}_{0}-\mathcal{F}_{0}
$$

on elementin kuormitusvektori. Matriisin $\mathcal{A}$ käänteismatriisi on

$$
\mathcal{A}^{-1}=\frac{1}{L^{e}}\left[\begin{array}{cc}
-1 & 1 \\
L^{e} & 0
\end{array}\right] \text {. }
$$

Elementin jäykkyysmatriisille saadaan kaavalla (C.13) yksinkertainen tulos

$$
\mathbf{K}^{e}=\frac{E A}{L^{e}}\left[\begin{array}{cc}
1 & -1 \\
-1 & 1
\end{array}\right] \text {. }
$$

Kun rakenne on analysoitu ja elementin vapausastesiirtymät $\mathbf{a}^{e}$ tunnetaan, voidaan integrointivakiot määrittää kaavalla (C.11). Sen jälkeen voidaan aksiaalisen siirtymän ja normaalivoiman jakaumat elementin alueella määrittää kaavoilla (C.1) ja (C.3).

\section{C.2 Elementin kuormitusvektori lineaarisesti jakautuneen kuormituksen tapauksessa}

Johdetaan lopuksi elementin kuormitusvektorille yksinkertainen tulos siinä tapauksessa, että aksiaalinen jakautunut kuorma $q_{x}(x)$ on elementin alueella lineaarinen ja muotoa (35). Yksityisratkaisu (36) elementtiin $e$ sovellettuna on

$$
u_{0}(x)=-\frac{1}{2} \frac{q_{x 1}^{e}}{E A} x^{2}-\frac{1}{6} \frac{q_{x 2}^{e}-q_{x 1}^{e}}{L^{e} E A} x^{3}
$$

ja sitä vastaavalle normaalivoimalle (C.4) saadaan

$$
N_{0}(x)=-q_{x 1}^{e} x-\frac{q_{x 2}^{e}-q_{x 1}^{e}}{2 L^{e}} x^{2} .
$$

Saadaan

$$
\boldsymbol{a}_{0}=-\frac{L^{e 2}}{E A}\left(\frac{q_{x 1}^{e}}{3}\left\{\begin{array}{l}
0 \\
1
\end{array}\right\}+\frac{q_{x 2}^{e}}{6}\left\{\begin{array}{l}
0 \\
1
\end{array}\right\}\right), \quad \mathcal{F}_{0}=-\frac{L^{e}}{2}\left(q_{x 1}^{e}\left\{\begin{array}{l}
0 \\
1
\end{array}\right\}+q_{x 2}^{e}\left\{\begin{array}{l}
0 \\
1
\end{array}\right\}\right)
$$

ja elementin kuormitusvektorille kaavalla (C.14) tulos

$$
\mathbf{R}^{e}=\frac{L^{e}}{6}\left(q_{x 1}^{e}\left\{\begin{array}{l}
2 \\
1
\end{array}\right\}+q_{x 2}^{e}\left\{\begin{array}{l}
1 \\
2
\end{array}\right\}\right) .
$$




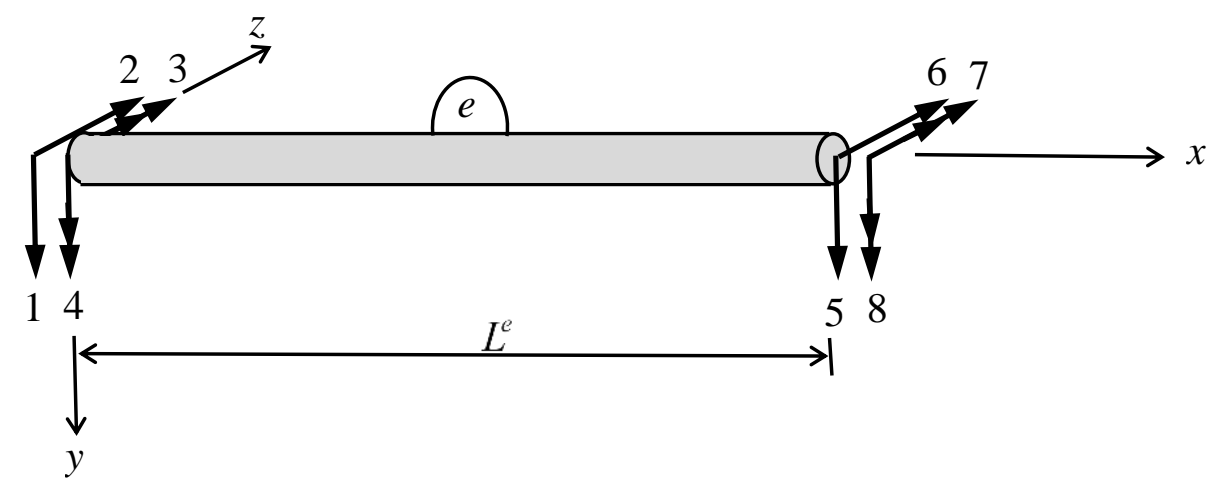

Kuva D.1. Taivutetun palkkielementin vapausasteet

\section{D.1 Elementtiyhtälöt}

Differentiaaliyhtälön (49) yleinen ratkaisu (50) esitetään tässä muodossa

$$
\mathbf{v}(x)=\left[\begin{array}{llll}
\mathbf{I} \frac{x^{3}}{6} & \mathbf{I} \frac{x^{2}}{2} & \mathbf{I} x & \mathbf{I}
\end{array}\right] \mathbf{C}+\mathbf{v}_{0}(x),
$$

missä

$$
\mathbf{C}=\left\{\begin{array}{l}
\mathbf{C}_{1} \\
\mathbf{C}_{2} \\
\mathbf{C}_{3} \\
\mathbf{C}_{4}
\end{array}\right\}
$$

on integrointivakioista muodostettu pystyvektori, $\mathbf{C}_{i}, i=1,2,3,4$ ovat sen alipystyvektoreita,

$$
\mathbf{v}_{0}(x)=\left\{\begin{array}{c}
v_{0}(x) \\
w_{0}(x)
\end{array}\right\}
$$

on kuormituksia $\mathbf{q}(x)$ ja $\mathbf{m}(x)$ vastaava yksityisratkaisu ja $\mathbf{I}$ on $2 \times 2$ yksikkömatriisi. Sijoittamalla lauseke (D.1) kaavoihin (48), (47) ja (46) saadaan poikkileikkauksen kiertymille, leikkausvoimille ja taivutusmomenteille ja lausekkeet

$$
\begin{gathered}
\boldsymbol{\Theta}(x)=\left[\begin{array}{llll}
\mathbf{I} \frac{x^{2}}{2}+\mathbf{S}^{-1} \mathbf{B} & \mathbf{I} x & \mathbf{I} & \mathbf{0}
\end{array}\right] \mathbf{C}+\boldsymbol{\Theta}_{0}(x), \\
\mathbf{Q}(x)=-\mathbf{B}\left[\begin{array}{llll}
\mathbf{I} & \mathbf{0} & \mathbf{0} & \mathbf{0}
\end{array}\right] \mathbf{C}+\mathbf{Q}_{0}(x), \\
\mathbf{M}(x)=-\mathbf{B}\left[\begin{array}{llll}
\mathbf{I} x & \mathbf{I} & \mathbf{0} & \mathbf{0}
\end{array}\right] \mathbf{C}+\mathbf{M}_{0}(x),
\end{gathered}
$$

missä

$$
\begin{gathered}
\Theta_{0}=\mathbf{v}_{0}^{\prime}+\mathbf{S}^{-1} \mathbf{B} \mathbf{v}_{0}^{\prime \prime \prime}+\mathbf{S}^{-1} \mathbf{B} \mathbf{S}^{-1} \mathbf{q}^{\prime}, \\
\mathbf{Q}_{0}=-\mathbf{B}\left(\mathbf{v}_{0}^{\prime \prime \prime}+\mathbf{S}^{-1} \mathbf{q}^{\prime}\right)+\mathbf{m},
\end{gathered}
$$




$$
\mathbf{M}_{0}=-\mathbf{B}\left(\mathbf{v}_{0}^{\prime \prime}+\mathbf{S}^{-1} \mathbf{q}\right)
$$

ovat yksityisratkaisua $\mathbf{v}_{0}(x)$ vastaavat poikkileikkauksen kiertymät, leikkausvoimat ja taivutusmomentit. Yhteensopivuusehdot elementin päissä ovat

$$
\left\{\begin{array}{l}
\mathbf{a}_{1}^{e} \\
\mathbf{a}_{2}^{e} \\
\mathbf{a}_{3}^{e} \\
\mathbf{a}_{4}^{e}
\end{array}\right\}=\left\{\begin{array}{c}
\mathbf{v}(0) \\
\boldsymbol{\Theta}(0) \\
\mathbf{v}\left(L^{e}\right) \\
\boldsymbol{\Theta}\left(L^{e}\right)
\end{array}\right\}
$$

ja niistä seuraa vapausastesiirtymien ja integrointivakioiden välille yhtälöt

$$
\mathbf{a}^{e}=\mathcal{A C}+\boldsymbol{a}_{0},
$$

missä

$$
\mathbf{a}^{e}=\left\{\begin{array}{c}
\mathbf{a}_{1}^{e} \\
\mathbf{a}_{2}^{e} \\
\mathbf{a}_{3}^{e} \\
\mathbf{a}_{4}^{e}
\end{array}\right\}, \quad \mathcal{A}=\left[\begin{array}{cccc}
\mathbf{0} & \mathbf{0} & \mathbf{0} & \mathbf{I} \\
\mathbf{B S}^{-1} & \mathbf{0} & \mathbf{I} & \mathbf{0} \\
\frac{L^{e 3}}{6} \mathbf{I} & \frac{L^{e 2}}{2} \mathbf{I} & L^{e} \mathbf{I} & \mathbf{I} \\
\frac{L^{e 2}}{2} \mathbf{I}+\mathbf{B S}^{-1} & L^{e} \mathbf{I} & \mathbf{I} & \mathbf{0}
\end{array}\right], \quad \boldsymbol{a}_{0}=\left\{\begin{array}{c}
\mathbf{v}_{0}(0) \\
\Theta_{0}(0) \\
\mathbf{v}_{0}\left(L^{e}\right) \\
\boldsymbol{\Theta}_{0}\left(L^{e}\right)
\end{array}\right\} .
$$

Tasapainoehdot elementin päissä ovat

$$
\left\{\begin{array}{l}
\mathbf{F}_{1}^{e} \\
\mathbf{F}_{2}^{e} \\
\mathbf{F}_{3}^{e} \\
\mathbf{F}_{4}^{e}
\end{array}\right\}=\left\{\begin{array}{c}
-\mathbf{Q}(0) \\
\mathbf{M}(0) \\
\mathbf{Q}\left(L^{e}\right) \\
-\mathbf{M}\left(L^{e}\right)
\end{array}\right\}
$$

ja niistä seuraa vapausastevoimien ja integrointivakioiden välille yhtälöt

$$
\mathbf{F}^{e}=\mathcal{B C}+\mathcal{F}_{0},
$$

missä

$$
\mathbf{F}^{e}=\left\{\begin{array}{l}
\mathbf{F}_{1}^{e} \\
\mathbf{F}_{2}^{e} \\
\mathbf{F}_{3}^{e} \\
\mathbf{F}_{4}^{e}
\end{array}\right\}, \quad \mathcal{B}=\mathbf{B}\left[\begin{array}{cccc}
\mathbf{I} & \mathbf{0} & \mathbf{0} & \mathbf{0} \\
\mathbf{0} & -\mathbf{I} & \mathbf{0} & \mathbf{0} \\
-\mathbf{I} & \mathbf{0} & \mathbf{0} & \mathbf{0} \\
\mathbf{I} L^{e} & \mathbf{I} & \mathbf{0} & \mathbf{0}
\end{array}\right], \quad \mathcal{F}_{0}=\left\{\begin{array}{c}
-\mathbf{Q}_{0}(0) \\
\mathbf{M}_{0}(0) \\
\mathbf{Q}_{0}\left(L^{e}\right) \\
-\mathbf{M}_{0}\left(L^{e}\right)
\end{array}\right\} .
$$

Yhtälöistä (D.11) saadaan integrointivakioille

$$
\mathbf{C}=\mathcal{A}^{-1}\left(\mathbf{a}^{e}-\boldsymbol{a}_{0}\right) .
$$

Yhtälöistä (D.14) ja (D.16) seuraa elementin vapausastevoimien ja -siirtymien välille yhtälö

missä

$$
\mathbf{F}^{e}=\mathbf{K}^{e} \mathbf{a}^{e}-\mathbf{R}^{e},
$$

on elementin jäykkyysmatriisi ja

$$
\mathbf{K}^{e}=\mathcal{B}^{-1}
$$




$$
\mathbf{R}^{e}=\mathbf{K}^{e} \boldsymbol{a}_{0}-\mathcal{F}_{0}
$$

on elementin kuormitusvektori. Matriisin $\mathcal{A}$ käänteismatriisi on

$$
\mathcal{A}^{-1}=(\mathbf{I}+\varphi)^{-1}\left[\begin{array}{cccc}
\frac{12}{L^{e 3}} \mathbf{I} & \frac{6}{L^{22}} \mathbf{I} & -\frac{12}{L^{e 3}} \mathbf{I} & \frac{6}{L^{22}} \mathbf{I} \\
-\frac{6}{L^{e 2}} \mathbf{I} & -\frac{1}{L^{e}}(4 \mathbf{I}+\boldsymbol{\varphi}) & \frac{6}{L^{e 2}} \mathbf{I} & -\frac{1}{L^{e}}(2 \mathbf{I}-\boldsymbol{\varphi}) \\
-\frac{1}{L^{e}} \boldsymbol{\varphi} & \mathbf{I}+\frac{1}{2} \boldsymbol{\varphi} & \frac{1}{L^{e}} \boldsymbol{\varphi} & -\frac{1}{2} \boldsymbol{\varphi} \\
\mathbf{I}+\boldsymbol{\varphi} & \mathbf{0} & \mathbf{0} & \mathbf{0}
\end{array}\right],
$$

missä on käytetty lyhennysmerkintää

$$
\varphi=\frac{12}{L^{e 2}} \mathbf{S}^{-1} \mathbf{B} .
$$

Elementin jäykkyysmatriisille saadaan kaavalla (D.18)

$$
\mathbf{K}^{e}=\mathbf{B}(\mathbf{I}+\varphi)^{-1}\left[\begin{array}{cccc}
\frac{12}{L^{e 3}} \mathbf{I} & \frac{6}{L^{22}} \mathbf{I} & -\frac{12}{L^{e 3}} \mathbf{I} & \frac{6}{L^{22}} \mathbf{I} \\
\frac{6}{L^{e 2}} \mathbf{I} & \frac{1}{L^{e}}(4 \mathbf{I}+\varphi) & -\frac{6}{L^{e 2}} \mathbf{I} & \frac{1}{L^{e}}(2 \mathbf{I}-\varphi) \\
-\frac{12}{L^{e 3}} \mathbf{I} & -\frac{6}{L^{22}} \mathbf{I} & \frac{12}{L^{e 3}} \mathbf{I} & -\frac{6}{L^{e 2}} \mathbf{I} \\
\frac{6}{L^{e 2}} \mathbf{I} & \frac{1}{L^{e}}(2 \mathbf{I}-\varphi) & -\frac{6}{L^{e 2}} \mathbf{I} & \frac{1}{L^{e}}(4 \mathbf{I}+\varphi)
\end{array}\right]
$$

Kun rakenne on analysoitu ja elementin vapausastesiirtymät $\mathbf{a}^{e}$ tunnetaan, voidaan integrointivakiot määrittää kaavalla (D.16). Sen jälkeen voidaan taipumien, poikkileikkauksen kiertymien, leikkausvoimien ja taivutusmomenttien jakaumat elementin alueella mär̈ittää kaavoilla (D.1), (D.4), (D.5) ja (D.6).

\section{D.2 Elementin kuormitusvektori lineaarisesti jakautuneen kuormituksen tapauksessa}

Johdetaan lopuksi elementin kuormitusvektorille yksinkertainen tulos siinä tapauksessa, että kuormat $\mathbf{q}(x)$ ja $\mathbf{m}(x)$ jakautuvat lineaarisesti elementin alueella. Yksityisratkaisu (53) elementtiin $e$ sovellettuna on

$$
\mathbf{v}_{0}(x)=\mathbf{B}^{-1}\left[\left(\frac{x^{4}}{24}-\frac{x^{5}}{120 L^{e}}\right) \mathbf{q}_{1}^{e}+\frac{x^{5}}{120 L^{e}} \mathbf{q}_{2}^{e}+\frac{x^{4}}{24 L^{e}}\left(\mathbf{m}_{2}^{e}-\mathbf{m}_{1}^{e}\right)\right] .
$$

Kaavoista (D.7), (D.8) ja (D.9) saadaan

$$
\begin{aligned}
\Theta_{0} & =\left[\left(\frac{x^{3}}{6}-\frac{x^{4}}{24 L^{e}}\right) \mathbf{B}^{-1}+\left(x-\frac{x^{2}}{2 L^{e}}\right) \mathbf{S}^{-1}-\frac{1}{L^{e}} \mathbf{S}^{-1} \mathbf{B} \mathbf{S}^{-1}\right) \mathbf{q}_{1}^{e} \\
& +\left(\frac{x^{4}}{24 L^{e}} \mathbf{B}^{-1}+\frac{x^{2}}{2 L^{e}} \mathbf{S}^{-1}+\frac{1}{L^{e}} \mathbf{S}^{-1} \mathbf{B} \mathbf{S}^{-1}\right) \mathbf{q}_{2}^{e}+\left(\frac{x^{3}}{6 L^{e}} \mathbf{B}^{-1}+\frac{x}{L^{e}} \mathbf{S}^{-1}\right)\left(\mathbf{m}_{2}^{e}-\mathbf{m}_{1}^{e}\right),
\end{aligned}
$$




$$
\begin{aligned}
\mathbf{M}_{0}= & {\left[\left(-\frac{x^{2}}{2}+\frac{x^{3}}{6 L^{e}}\right) \mathbf{I}+\frac{x}{L^{e}} \mathbf{B} \mathbf{S}^{-1}-\mathbf{B S}^{-1}\right] \mathbf{q}_{1}^{e}-\left(\frac{x^{3}}{6 L^{e}} \mathbf{I}+\frac{x}{L^{e}} \mathbf{B S}^{-1}\right) \mathbf{q}_{2}^{e} } \\
& -\left(\frac{x^{2}}{2 L^{e}}+x\right)\left(\mathbf{m}_{2}^{e}-\mathbf{m}_{1}^{e}\right), \\
\mathbf{Q}_{0}= & {\left[\left(-x+\frac{x^{2}}{2 L^{e}}\right) \mathbf{I}+\frac{1}{L^{e}} \mathbf{B S}^{-1}\right] \mathbf{q}_{1}^{e}-\left(\frac{x^{2}}{2 L^{e}} \mathbf{I}+\frac{1}{L^{e}} \mathbf{B S}^{-1}\right) \mathbf{q}_{2}^{e}+\mathbf{m}_{1}^{e} }
\end{aligned}
$$

ja kaavoista (D.12c) ja (D.15c) edelleen

$$
\begin{aligned}
& \boldsymbol{a}_{0}=\mathbf{B}^{-1}\left\{\begin{array}{c}
\mathbf{0} \\
-\frac{L^{e 3}}{144} \varphi^{2} \\
\frac{L^{e 4}}{30} \mathbf{I} \\
\left(\frac{1}{8} \mathbf{I}+\frac{1}{24} \varphi-\frac{1}{144} \varphi^{2}\right) L^{e 3}
\end{array}\right\} \mathbf{q}_{1}^{e}+\mathbf{B}^{-1}\left\{\begin{array}{c}
\mathbf{0} \\
\frac{L^{e 3}}{144} \varphi^{2} \\
\frac{L^{e 4}}{120} \mathbf{I} \\
\left(\frac{1}{24} \mathbf{I}+\frac{1}{24} \varphi+\frac{1}{144} \varphi^{2}\right) L^{e 3}
\end{array}\right\} \mathbf{q}^{e} \\
& +\mathbf{B}^{-1}\left\{\begin{array}{c}
\mathbf{0} \\
\mathbf{0} \\
-\frac{L^{e 3}}{24} \mathbf{I} \\
-\left(\frac{1}{6} \mathbf{I}+\frac{1}{12} \varphi\right) L^{e 2}
\end{array}\right\} \mathbf{m}_{1}^{e}+\mathbf{B}^{-1}\left\{\begin{array}{c}
\mathbf{0} \\
\mathbf{0} \\
\frac{L^{e 3}}{24} \mathbf{I} \\
\left(\frac{1}{6} \mathbf{I}+\frac{1}{12} \varphi\right) L^{e 2}
\end{array}\right\} \mathbf{m}_{2}^{e} \\
& \mathcal{F}_{0}=\left\{\begin{array}{c}
-\frac{L^{e}}{12} \boldsymbol{\varphi} \\
-\frac{L^{e 2}}{12} \boldsymbol{\varphi} \\
-\frac{L^{e}}{2} \mathbf{I}+\frac{L^{e}}{12} \boldsymbol{\varphi} \\
\frac{L^{e 2}}{3} \mathbf{I}
\end{array}\right\} \mathbf{q}_{1}^{e}+\left\{\begin{array}{c}
\frac{L^{e}}{12} \boldsymbol{0} \\
\mathbf{0} \\
-\frac{L^{e}}{2} \mathbf{I}-\frac{L^{e}}{12} \boldsymbol{\varphi} \\
\frac{L^{e 2}}{6} \mathbf{I}+\frac{L^{e 2}}{12} \boldsymbol{\varphi}
\end{array}\right\} \mathbf{q}_{2}^{e}+\left\{\begin{array}{c}
-\mathbf{I} \\
\mathbf{0} \\
\mathbf{I} \\
-\frac{L^{e}}{2} \mathbf{I}
\end{array}\right\} \mathbf{m}_{1}^{e}+\left\{\begin{array}{c}
\mathbf{0} \\
\mathbf{0} \\
\mathbf{0} \\
\frac{L^{e}}{2} \mathbf{I}
\end{array}\right\} \mathbf{m}_{2}^{e} .
\end{aligned}
$$

Elementin kuormitusvektorille saadaan kaavalla (D.19) tulos

$$
\mathbf{R}^{e}=(\mathbf{I}+\varphi)^{-1}\left(\left[\begin{array}{c}
\frac{7 L^{e}}{20} \mathbf{I}+\frac{L^{e}}{3} \boldsymbol{\varphi} \\
\frac{L^{e 2}}{20} \mathbf{I}+\frac{L^{e 2}}{24} \boldsymbol{\varphi} \\
\frac{3 L^{e}}{20} \mathbf{I}+\frac{L^{e}}{6} \boldsymbol{\varphi} \\
-\frac{L^{e 2}}{30} \mathbf{I}-\frac{L^{e 2}}{24} \boldsymbol{\varphi}
\end{array}\right] \mathbf{q}_{1}^{e}+\left[\begin{array}{c}
\frac{3 L^{e}}{20} \mathbf{I}+\frac{L^{e}}{6} \boldsymbol{\varphi} \\
\frac{L^{e 2}}{30} \mathbf{I}+\frac{L^{e 2}}{24} \boldsymbol{\varphi} \\
\frac{7 L^{e}}{20} \mathbf{I}+\frac{L^{e}}{3} \boldsymbol{\varphi} \\
-\frac{L^{e 2}}{20} \mathbf{I}-\frac{L^{e 2}}{24} \boldsymbol{\varphi}
\end{array}\right] \mathbf{q}_{2}^{e}\right)+\left[\begin{array}{c}
\frac{1}{2} \mathbf{I} \\
-\frac{L^{e}}{12}(\mathbf{I}-\boldsymbol{\varphi}) \\
-\frac{1}{2} \mathbf{I} \\
\frac{L^{e}}{12}(\mathbf{I}-\varphi)
\end{array}\right] \mathbf{m}_{1}^{e}+\left[\begin{array}{c}
\frac{1}{2} \mathbf{I} \\
\frac{L^{e}}{12}(\mathbf{I}-\boldsymbol{\varphi}) \\
-\frac{1}{2} \mathbf{I} \\
-\frac{L^{e}}{12}(\mathbf{I}-\boldsymbol{\varphi})
\end{array}\right] \mathbf{m}_{2}^{e}
$$




\section{D.3 Symmetrinen poikkileikkaus}

Tarkastellaan lopuksi $y$-akselin suhteen symmetristä poikkileikkausta. Tällöin $E I_{y z}=0$ ja $k_{y z}=0$, joten taivutus- ja leikkausjäykkyysmatriiseille saadaan

$$
\mathbf{B}=\left[\begin{array}{cc}
E I_{z} & 0 \\
0 & E I_{y}
\end{array}\right], \quad \mathbf{S}=G A\left[\begin{array}{cc}
k_{y} & 0 \\
0 & k_{z}
\end{array}\right]
$$

ja matriisille $\varphi$ edelleen

$$
\boldsymbol{\varphi}=\left[\begin{array}{cc}
\varphi_{z} & 0 \\
0 & \varphi_{y}
\end{array}\right]
$$

missä

$$
\varphi_{z}=\frac{12 E I_{z}}{k_{y} G A L^{2}}, \quad \varphi_{y}=\frac{12 E I_{y}}{k_{z} G A L^{2}} .
$$

Elementtiyhtälön (D.17) 1., 3., 5. ja 7. yhtälö voidaan nyt saattaa muotoon

$$
\mathbf{F}_{y}^{e}=\mathbf{K}_{y}^{e} \mathbf{a}_{y}^{e}-\mathbf{R}_{y}^{e} \text {, }
$$

missä

$$
\mathbf{F}_{y}^{e}=\left\{\begin{array}{c}
F_{1}^{e} \\
F_{3}^{e} \\
F_{5}^{e} \\
F_{7}^{e}
\end{array}\right\}, \quad \mathbf{a}_{y}^{e}=\left\{\begin{array}{c}
a_{1}^{e} \\
a_{3}^{e} \\
a_{5}^{e} \\
a_{7}^{e}
\end{array}\right\},
$$

ja elementin jäykkyysmatriisi ja kuormitusvektori ovat

$$
\mathbf{K}_{y}^{e}=\frac{E I_{z}}{1+\varphi_{z}}\left[\begin{array}{cccc}
\frac{12}{L^{e 3}} & \frac{6}{L^{e 2}} & -\frac{12}{L^{e 3}} & \frac{6}{L^{e 2}} \\
\frac{6}{L^{e 2}} & \frac{4+\varphi_{z}}{L^{e}} & -\frac{6}{L^{e 2}} & \frac{2-\varphi_{z}}{L^{e}} \\
-\frac{12}{L^{e 3}} & -\frac{6}{L^{e 2}} & \frac{12}{L^{e 3}} & -\frac{6}{L^{e 2}} \\
\frac{6}{L^{e 2}} & \frac{2-\varphi_{z}}{L^{e}} & -\frac{6 E I_{z}}{L^{e 2}} & \frac{4+\varphi_{z}}{L^{e}}
\end{array}\right]
$$

ja

$$
\left.\mathbf{R}_{y}^{e}=\frac{1}{1+\varphi_{z}}\left(\begin{array}{c}
\frac{7 L^{e}}{20}+\frac{L^{e}}{3} \varphi_{z} \\
\frac{L^{e 2}}{20}+\frac{L^{e 2}}{24} \varphi_{z} \\
\frac{3 L^{e}}{20}+\frac{L^{e}}{3} \varphi_{z} \\
-\frac{L^{e 2}}{30}-\frac{L^{e 2}}{24} \varphi_{z}
\end{array}\right\} q_{y 1}^{e}+\left\{\begin{array}{c}
\frac{3 L^{e}}{20}+\frac{L^{e}}{6} \varphi_{z} \\
\frac{L^{e 2}}{30}+\frac{L^{e 2}}{24} \varphi_{z} \\
\frac{7 L^{e}}{20}+\frac{4 L^{e}}{3} \varphi_{z} \\
-\frac{L^{e 2}}{20}-\frac{L^{e 2}}{24} \varphi_{z}
\end{array}\right\} q_{y 1}^{e}\right)+\left\{\begin{array}{c}
\frac{1}{2} \\
-\frac{L^{e}}{12}\left(1-\varphi_{z}\right) \\
-\frac{1}{2} \\
\frac{L^{e}}{12}\left(1-\varphi_{z}\right)
\end{array}\right\} m_{z 1}^{e}+\left\{\begin{array}{c}
\frac{1}{2} \\
\frac{L^{e}}{12}\left(1-\varphi_{z}\right) \\
-\frac{1}{2} \\
-\frac{L^{e}}{12}\left(1-\varphi_{z}\right)
\end{array}\right\} m_{z 2}^{e} .
$$

Elementtiyhtälön (D.17) 2., 4., 6. ja 8. yhtälöistä saadaan kaavoja (D.32), (D.34) ja (D.35) 
vastaava tulos. Havaitaan, että tässä tapauksessa taivutukset $x, y$-tasossa ja $x, z$-tasossa eivät ole kytkettyjä ja ne voidaan käsitellä erikseen. Elementin jäykkyysmatriisi (D.34) on johdettu lähteessä [2] ja esitetty sen kaavassa (5.119). Tässä lähteessä on myös esitetty elementti vedetylle/puristetulle, väännetylle ja kahteen suuntaan taivutetulle palkille. Sen jäykkyysmatriisi on kaava (5.116). Siinä on kuitenkin rajoituttu Saint-Venantin vääntöön sekä poikkileikkaukseen, jossa $E I_{y z}=0$ ja $k_{y z}=0$. Tässä esitetty taivutusteoria on yleisempi ja soveltuu siis myös palkkeihin, joiden poikkileikkaus on epäsymmetrinen. 


\section{E Väännetyn palkin elementtiratkaisu}

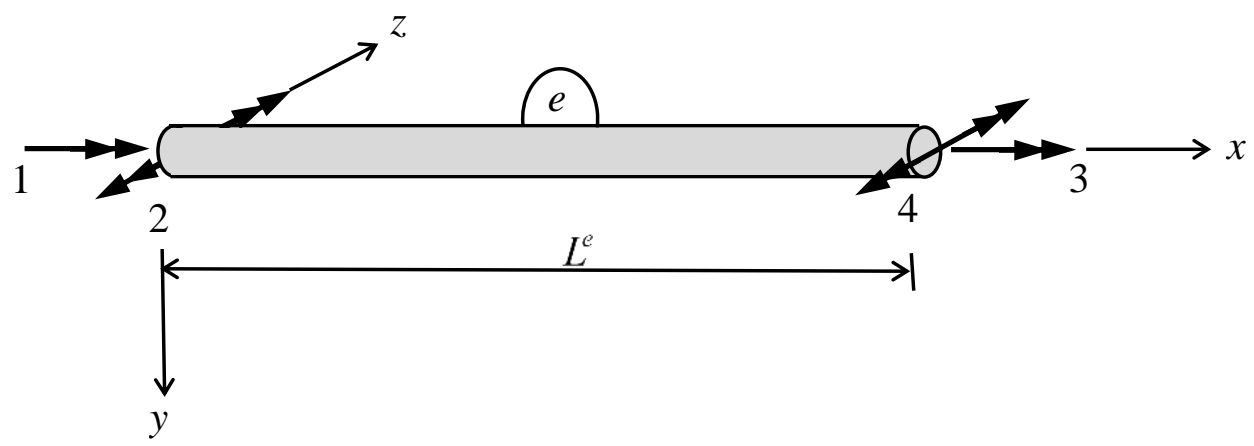

Kuva E.1. Väännetyn palkkielementin vapausasteet

\section{E.1 Elementtiyhtälöt}

Vääntökulman $\theta_{x}(x)$ differentiaaliyhtälön (54) yleinen ratkaisu (59) esitetään tässä muodossa

$$
\theta_{x}(x)=\left[\begin{array}{lll}
1 & x & \sinh \left(\frac{k}{L^{e}} x\right) \\
\cosh \left(\frac{k}{L^{e}} x\right)
\end{array}\right] \mathbf{C}+\theta_{x 0}(x)
$$

missä

$$
k=L \sqrt{\frac{G J}{E I_{\phi}}},
$$

$L^{e}$ on elementin pituus ja

$$
\mathbf{C}=\left\{\begin{array}{l}
C_{1} \\
C_{2} \\
C_{3} \\
C_{4}
\end{array}\right\} .
$$

Sitä vastaten saadaan vääntökulman derivaatalle

$$
\theta_{x}^{\prime}(x)=\left[\begin{array}{llll}
0 & 1 & \frac{k}{L^{e}} \cosh \frac{k}{L^{e}} x & \frac{k}{L^{e}} \sinh \frac{k}{L^{e}} x
\end{array}\right] \mathbf{C}+\theta_{x 0}^{\prime}(x),
$$

Saint-Venantin vääntömomentille kaavalla (56)

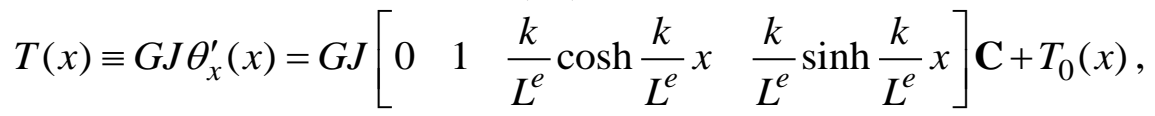

käyristymismomentille kaavalla (57)

$$
B(x) \equiv-E I_{\phi} \theta_{x}^{\prime \prime}(x)=-G J\left[\begin{array}{llll}
0 & 0 & \sinh \frac{k}{L^{e}} x & \cosh \frac{k}{L^{e}} x
\end{array}\right] \mathbf{C}+B_{0}(x)
$$

ja kokonaisvääntömomentille kaavalla (58)

$$
M_{x}(x) \equiv B^{\prime}(x)+T(x)=G J\left[\begin{array}{llll}
0 & 1 & 0 & 0
\end{array}\right] \mathbf{C}+M_{x 0}(x) .
$$

Näissä lausekkeissa suureita

$$
T_{0}(x)=G J \theta_{x 0}^{\prime}(x),
$$




$$
B_{0}(x)=-E I_{\phi} \theta_{x 0}^{\prime \prime}(x)
$$

ja

$$
M_{x 0}(x)=-E I_{\phi} \theta_{x 0}^{\prime \prime \prime}(x)+G J \theta_{x 0}^{\prime}(x)
$$

kutsutaan tässä yksityisratkaisua $\theta_{x 0}(x)$ vastaaviksi Saint-Venantin vääntömomentiksi, käyristymismomentiksi ja kokonaisvääntömomentiksi.

Yhteensopivuusehdot elementin päissä ovat

$$
\left\{\begin{array}{l}
a_{1}^{e} \\
a_{2}^{e} \\
a_{3}^{e} \\
a_{4}^{e}
\end{array}\right\}=\left\{\begin{array}{c}
\theta_{x}(0) \\
\theta_{x}^{\prime}(0) \\
\theta_{x}\left(L^{e}\right) \\
\theta_{x}^{\prime}\left(L^{e}\right)
\end{array}\right\}
$$

ja niistä seuraa vapausastesiirtymien ja integrointivakioiden välille yhtälöt

$$
\mathbf{a}^{e}=\mathcal{A C}+\boldsymbol{a}_{0}
$$

missä

$$
\mathbf{a}^{e}=\left\{\begin{array}{l}
a_{1}^{e} \\
a_{2}^{e} \\
a_{3}^{e} \\
a_{4}^{e}
\end{array}\right\}, \quad \mathcal{A}=\left[\begin{array}{cccc}
1 & 0 & 0 & 1 \\
0 & 1 & \frac{k}{L^{e}} & 0 \\
1 & L^{e} & \operatorname{sh} & \frac{k}{L^{e}} \\
0 & 1 & \frac{k}{L^{e}} \operatorname{ch} & \frac{k}{L^{e}} \operatorname{sh}
\end{array}\right], \quad \boldsymbol{a}_{0}=\left\{\begin{array}{c}
\theta_{x 0}(0) \\
\theta_{x 0}^{\prime}(0) \\
\theta_{x 0}\left(L^{e}\right) \\
\theta_{x 0}^{\prime}\left(L^{e}\right)
\end{array}\right\}
$$

ja otettiin käyttöön lyhennysmerkinnät $\operatorname{sh}=\sinh k$ ja $\mathrm{ch}=\cosh k$. Tasapainoehdot elementin päissä ovat

$$
\left\{\begin{array}{l}
F_{1}^{e} \\
F_{2}^{e} \\
F_{3}^{e} \\
F_{4}^{e}
\end{array}\right\}=\left\{\begin{array}{c}
-M_{x}(0) \\
B(0) \\
M_{x}\left(L^{e}\right) \\
-B\left(L^{e}\right)
\end{array}\right\}
$$

ja niistä seuraa vapausastevoimien ja integrointivakioiden välille yhtälöt

$$
\mathbf{F}^{e}=\mathcal{B C}+\mathcal{F}_{0},
$$

missä

$$
\mathbf{F}^{e}=\left\{\begin{array}{l}
F_{1}^{e} \\
F_{2}^{e} \\
F_{3}^{e} \\
F_{4}^{e}
\end{array}\right\}, \quad \mathcal{B}=G J\left[\begin{array}{cccc}
0 & -1 & 0 & 0 \\
0 & 0 & 0 & -1 \\
0 & 1 & 0 & 0 \\
0 & 0 & \mathrm{sh} & \mathrm{ch}
\end{array}\right], \quad \boldsymbol{a}_{0}=\left\{\begin{array}{c}
-M_{x 0}(0) \\
B_{0}(0) \\
M_{x 0}\left(L^{e}\right) \\
-B_{0}\left(L^{e}\right)
\end{array}\right\} .
$$

Yhtälöistä (E.12) saadaan integrointivakioiksi

$$
\mathbf{C}=\mathcal{A}^{-1}\left(\mathbf{a}^{e}-\boldsymbol{a}_{0}\right) \text {. }
$$

Yhtälöistä (E.15) ja (E.17) seuraa elementin vapausastevoimien ja -siirtymien välille yhtälö

$$
\mathbf{F}^{e}=\mathbf{K}^{e} \mathbf{a}^{e}-\mathbf{R}^{e}
$$


missä

on elementin jäykkyysmatriisi ja

$$
\mathbf{K}^{e}=\mathcal{B A}^{-1}
$$

$$
\mathbf{R}^{e}=\mathbf{K}^{e} \boldsymbol{a}_{0}-\mathcal{F}_{0}
$$

on elementin kuormitusvektori. Matriisin $\mathcal{A}$ käänteismatriisiksi saadaan

$$
\mathcal{A}^{-1}=\frac{1}{2+k \operatorname{sh}-2 \mathrm{ch}}\left[\begin{array}{cccc}
k \mathrm{sh}+1-\mathrm{ch} & \frac{L^{e}}{k}(k \mathrm{ch}-\mathrm{sh}) & 1-\mathrm{ch} & \frac{L^{e}}{k}(\mathrm{sh}-k) \\
-\frac{k}{L^{e}} \mathrm{sh} & 1-\mathrm{ch} & \frac{k}{L^{e}} \mathrm{sh} & 1-\mathrm{ch} \\
\mathrm{sh} & -\frac{L^{e}}{k}(\mathrm{ch}-1-k \mathrm{sh}) & -\mathrm{sh} & \frac{L^{e}}{k}(\mathrm{ch}-1) \\
1-\mathrm{ch} & -\frac{L^{e}}{k}(k \mathrm{ch}-\mathrm{sh}) & \mathrm{ch}-1 & -\frac{L^{e}}{k}(\mathrm{sh}-k)
\end{array}\right] .
$$

Elementin jäykkyysmatriisiksi saadaan kaavalla (E.20) tulos

$$
\mathbf{K}^{e}=\frac{G J}{2+k \mathrm{sh}-2 \mathrm{ch}}\left[\begin{array}{cccc}
\frac{k}{L^{e}} \mathrm{sh} & \mathrm{ch}-1 & -\frac{k}{L^{e}} \mathrm{sh} & \mathrm{ch}-1 \\
\mathrm{ch}-1 & \frac{L^{e}}{k}(k \mathrm{ch}-\mathrm{sh}) & 1-\mathrm{ch} & \frac{L^{e}}{k}(\mathrm{sh}-k) \\
-\frac{k}{L^{e}} \mathrm{sh} & 1-\mathrm{ch} & \frac{k}{L^{e}} \mathrm{sh} & 1-\mathrm{ch} \\
\mathrm{ch}-1 & \frac{L^{e}}{k}(\mathrm{sh}-k) & 1-\cosh k & \frac{L^{e}}{k}(k \mathrm{ch}-\mathrm{sh})
\end{array}\right] .
$$

Kun rakenne on analysoitu ja elementin vapausastesiirtymät $\mathbf{a}^{e}$ tunnetaan, voidaan integrointivakiot määrittää kaavalla (E.17). Sen jälkeen voidaan vääntökulman, vääntökulman derivaatan, Saint-Venantin vääntömomentin, käyristymismomentin ja kokonaisvääntömomentin jakaumat elementin alueella määrittää kaavoilla (E.1), (E.4), (E.5), (E.6) ja (E.7).

\section{E.2 Elementin kuormitusvektori lineaarisesti jakautuneen kuormituksen tapauksessa}

Johdetaan lopuksi elementin kuormitusvektorille yksinkertainen tulos siinä tapauksessa, että kuormat $m_{x}(x)$ ja $b(x)$ jakautuvat lineaarisesti elementin alueella. Yksityisratkaisu (64) elementtiin $e$ sovellettuna on

$$
\theta_{x 0}(x)=\left(-\frac{1}{2} \frac{x^{2}}{G J}+\frac{1}{6} \frac{x^{3}}{L^{e} G J}\right) m_{x 1}^{e}-\frac{1}{6} \frac{x^{3}}{L^{e} G J} m_{x 2}^{e}+\frac{1}{2} \frac{x^{2}}{L^{e} G J} b_{1}^{e}-\frac{1}{2} \frac{x^{2}}{L^{e} G J} b_{2}^{e}
$$

ja sitä vastaaville suureille saadaan 


$$
\begin{aligned}
& \theta_{x 0}^{\prime}(x)=\frac{L^{e}}{G J}\left(\frac{x}{L^{e}}-\frac{1}{2} \frac{x^{2}}{L^{e 2}}\right) m_{x 1}^{e}-\frac{1}{2} \frac{L^{e}}{G J} \frac{x^{2}}{L^{e 2}} m_{x 2}^{e}+\frac{1}{G J} \frac{x}{L^{e}} b_{1}^{e}-\frac{1}{G J} \frac{x}{L^{e}} b_{1}^{e}, \\
& M_{x 0}(x)=\left(\frac{1}{k^{2}}-\frac{x}{L^{e}}+\frac{1}{2} \frac{x^{2}}{L^{e 2}}\right) L^{e} m_{x 1}^{e}+\left(\frac{1}{k^{2}}-\frac{1}{2} \frac{x^{2}}{L^{e 2}}\right) L^{e} m_{x 2}^{e}+\frac{x}{L^{e}} b_{1}^{e}-\frac{x}{L^{e}} b_{2}^{e}, \\
& B_{0}(x)=\frac{L^{e 2}}{k^{2}}\left[\left(1-\frac{x}{L^{e}}\right) m_{x 1}^{e}+\frac{x}{L^{e}} m_{x 2}^{e}-\frac{1}{L^{e}} b_{1}^{e}+\frac{1}{L^{e}} b_{2}^{e}\right] .
\end{aligned}
$$

Saadaan

$$
\begin{aligned}
& \left.\left.\boldsymbol{a}_{0}=\frac{1}{G J}\left\{\begin{array}{c}
0 \\
0 \\
-\frac{L^{e 2}}{3} \\
\frac{L^{e}}{2}
\end{array}\right\} m_{x 1}^{e}+\left\{\begin{array}{c}
0 \\
0 \\
-\frac{L^{e 2}}{6}
\end{array}\right\} m_{x 2}^{e}+\left\{\begin{array}{c}
0 \\
0 \\
\frac{L^{e}}{2} \\
-\frac{L^{e}}{2}
\end{array}\right\} b_{1}^{e}+\left\{\begin{array}{c}
0 \\
0 \\
1
\end{array}\right\} \frac{L}{2}^{e}\right\} b_{2}^{e}\right), \\
& \mathcal{F}_{0}=\left\{\begin{array}{c}
-\frac{L^{e}}{k^{2}} \\
\frac{L^{e 2}}{k^{2}} \\
\frac{2-k^{2}}{2 k^{2}} L^{e} \\
0
\end{array}\right\} m_{x 1}^{e}+\left\{\begin{array}{c}
-\frac{L^{e}}{k^{2}} \\
0 \\
\frac{2-k^{2}}{2 k^{2}} L^{e} \\
\frac{L^{e 2}}{k^{2}}
\end{array}\right\} m_{x 2}^{e}+\left\{\begin{array}{c}
0 \\
-\frac{L^{e}}{k^{2}} \\
1 \\
-\frac{L^{e}}{k^{2}}
\end{array}\right\} b_{1}^{e}+\left\{\begin{array}{c}
\frac{L^{e}}{k^{2}} \\
-1 \\
\frac{L^{e}}{k^{2}}
\end{array}\right\} b_{2}^{e},
\end{aligned}
$$

ja elementin kuormitusvektoriksi kaavalla (E.20) tulos

$$
\begin{aligned}
& \mathbf{R}^{e}=\frac{1}{2+k \operatorname{sh}-2 \mathrm{ch}}\left[\begin{array}{c}
\left(\frac{k^{2}-12}{6 k^{2}}-\frac{3}{2 k} \mathrm{sh}+\frac{k^{2}+6}{3 k^{2}} \mathrm{ch}\right) L^{e 2} \\
\left(\frac{k^{2}+4}{2 k^{2}}+\frac{k^{2}+6}{6 k} \mathrm{sh}-\frac{k^{2}+4}{2 k^{2}} \mathrm{ch}\right) L^{e} \\
\left(-\frac{1}{3}+\frac{1}{2 k} \mathrm{sh}-\frac{1}{6} \mathrm{ch}\right) L^{e 2}
\end{array}\right\} m_{x 1}^{e}+\left\{\begin{array}{c}
\left(\frac{k^{2}-4}{2 k^{2}}+\frac{k^{2}-3}{6 k} \mathrm{sh}-\frac{k^{2}-4}{2 k^{2}} \mathrm{ch}\right) L^{e} \\
\left(\frac{1}{2 k} \mathrm{sh}+\frac{1}{6} \mathrm{ch}\right) L^{e 2} \\
\left(\frac{k^{2}-4}{2 k^{2}}+\frac{k^{2}-3}{3 k} \mathrm{sh}-\frac{k^{2}-4}{2 k^{2}} \mathrm{ch}\right) L^{e} \\
-\left(\frac{k^{2}-12}{6 k^{2}}-\frac{3}{2 k} \mathrm{sh}+\frac{k^{2}+6}{3 k^{2}} \mathrm{ch}\right) L^{e 2}
\end{array}\right\} m_{x 2}^{e} \\
& \left.+\left\{\begin{array}{c}
1+\frac{k}{2} \mathrm{sh}-\mathrm{ch} \\
\left(\frac{k^{2}-4}{2 k^{2}}-\frac{2}{k} \mathrm{sh}+\frac{k^{2}+4}{2 k^{2}} \mathrm{ch}\right) L^{e} \\
1+\frac{k}{2} \mathrm{sh}-\mathrm{ch} \\
-\left(\frac{k^{2}-4}{2 k^{2}}-\frac{2}{k} \mathrm{sh}+\frac{k^{2}+4}{2 k^{2}} \mathrm{ch}\right) L^{e}
\end{array}\right\}\left(b_{2}^{e}-b_{1}^{e}\right)\right]
\end{aligned}
$$




\section{F Esimerkkitehtävän poikkileikkauksen käyristymisfunktiot}

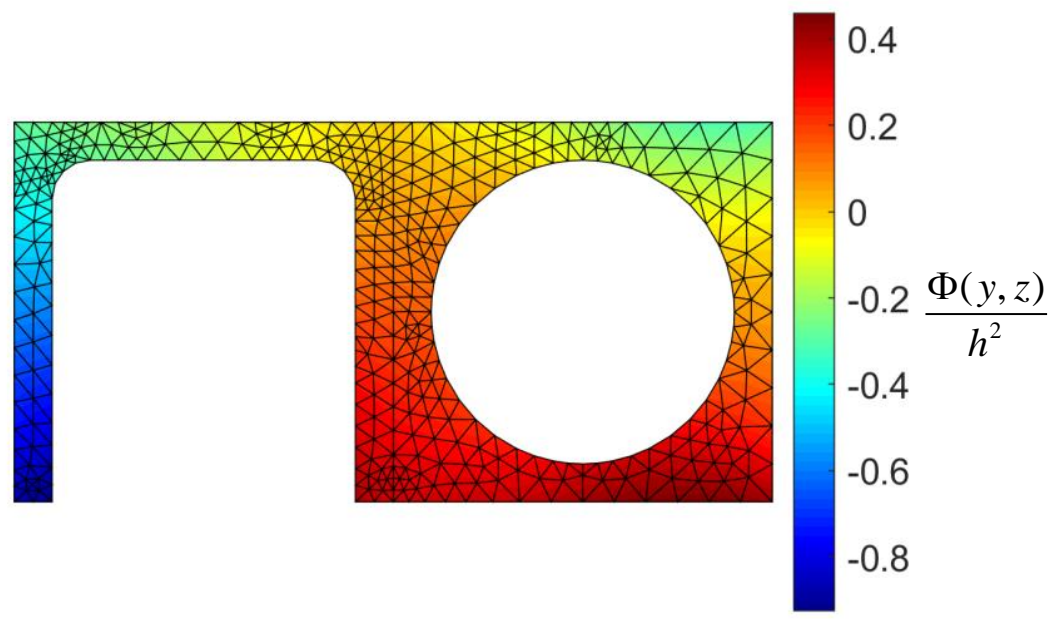

Kuva F.1. Käyristymisfunktion $\Phi(y, z)$ jakauma

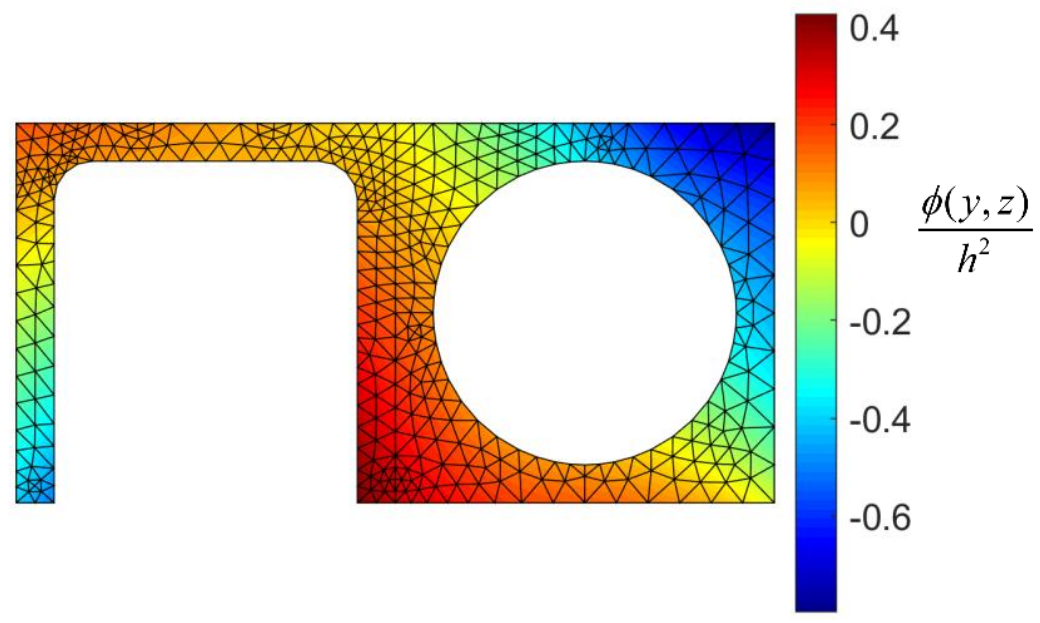

Kuva F.2. Käyristymisfunktion $\phi(y, z)$ jakauma

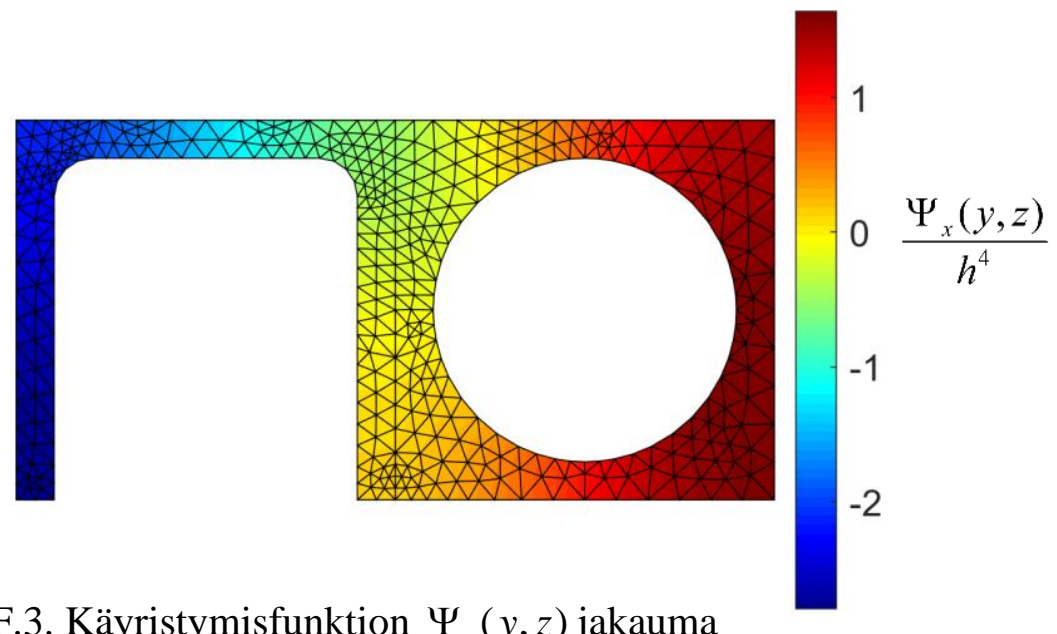

Kuva F.3. Käyristymisfunktion $\Psi_{x}(y, z)$ jakauma 


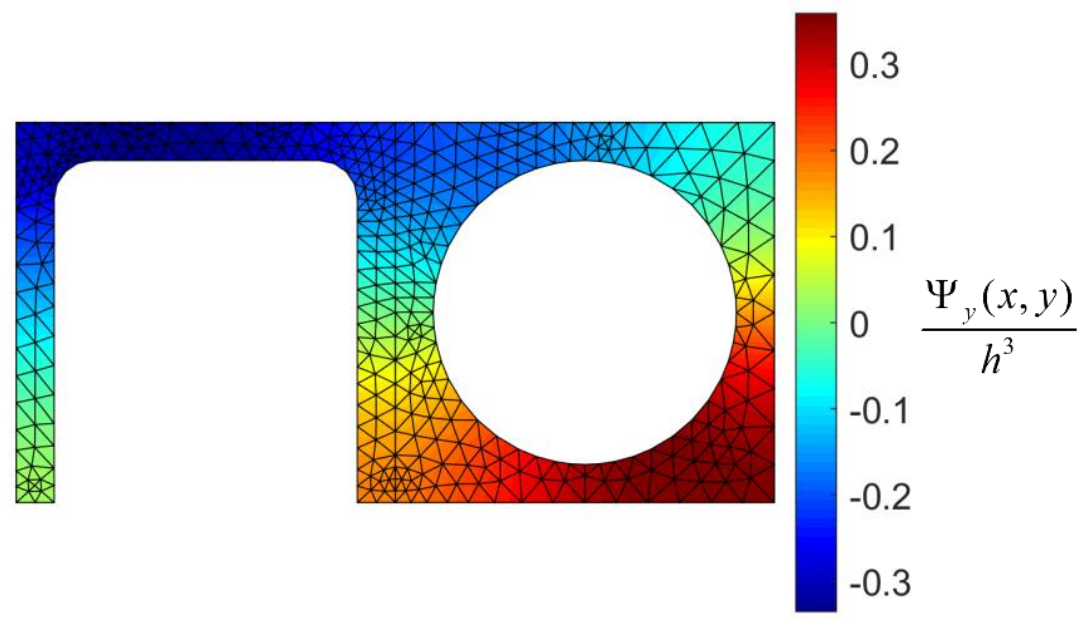

Kuva F.4. Käyristymisfunktion $\Psi_{y}(y, z)$ jakauma

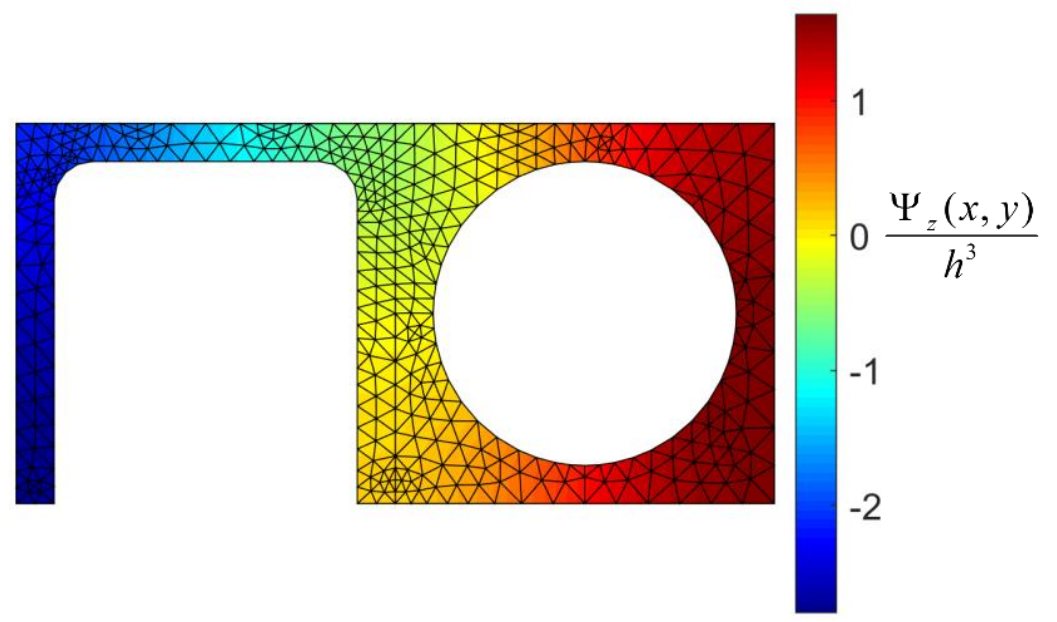

Kuva F.5. Käyristymisfunktion $\Psi_{z}(y, z)$ jakauma 